\title{
Transnationales Verbrauchervertragsrecht
}

\author{
Von Gralf-Peter Calliess, Frankfurt a.M.*
}

Inhaltsverzeichnis

I. Einleitung . . . . . . . . . . . . . . . . . 245

II. Was ist transnationales Recht? . . . . . . . . . . . . . . . . . . . . . 247

1. Die klassische Begriffsdichotomie: nationales und internationales Recht . . . . . . . . . . . . . . . . 247

2. Europarecht als supranationales Recht . . . . . . . . . . . . . 249

3. Der neue Transnationalismus: einige Bedeutungskontexte . . . . . . 249

a) Der funktionalistische Ansatz: Norm vs. Sachverhalt . . . . . . . 249

b) Der kulturkritische Ansatz: Multilateralismus vs. Unilateralismus . . . . . . . . . . . . . . . . 251

c) Der post-etatistische Ansatz: staatliches vs. selbstgeschaffenes Recht .................... 252

4. Transnationales Recht: eine Definition im Tetralemma des internationalen Rechts . . . . . . . . . . . . . . . . . . . . . . 254

III. Transnationales Verbrauchervertragsrecht . . . . . . . . . . . . 255

1. Rechtliche und soziale Entstehungsbedingungen transnationalen Rechts . . . . . . . . . . . . . . 255

a) Die Ausgangslage: internationales Handelsrecht und nationales Verbraucherrecht . . . . . . . . . . . . 257

b) Herausforderungen: Europäischer Binnenmarkt und elektronischer Weltmarktplatz ............... . . 259

c) Die Interessenlage: Verbraucherlandprinzip als Gebot der Gerechtigkeit? . . . . . . . . . . . . . . 261

* Die Erstellung dieser Arbeit wurde von der Volkswagenstiftung gefördert.

Abgekürzt werden zitiert: Calliess, Reflexive Transnational Law, The Privatisation of Civil Law and the Civilisation of Private Law: Zeitschrift für Rechtssoziolgie (ZRechtssoziol.) 2002, 185ff.; The Practice of Transnational Law, hrsg. von Berger (2001).

Weitere Abkürzungen: AAA = American Arbitration Association; ABA = American Bar Association; $\mathrm{ADR}=$ Alternative Dispute Resolution; ICANN = Internet Corporation for Assigned Names and Numbers; ICC = International Chamber of Commerce; $\mathrm{i}-\mathrm{ADR}=$ International Alternative Dispute Resolution; ODR = Online Dispute Resolution; UDRP $=$ Uniform Domain Name Dispute Resolution Policy. 
d) Alternativen: gegenseitige Anerkennung und europäisches Einheitsrecht..................... . . 264

e) Leerstellen: Grenzen der europäischen Rechtsvereinheitlichung . . 266

2. Phänomene eines transnationalen Verbrauchervertragsrechts . . . . . . 267

a) Selbstregulierung im internationalen Handel . . . . . . . . . . . . 267

b) Selbstregulierung auf nationalen und europäischen Verbrauchermärkten . . . . . . . . . . . . . . . . . . . . . 268

c) Selbstregulierung auf dem elektronischen Weltmarktplatz . . . . . 270

d) Die Rolle virtueller Marktplätze . . . . . . . . . . . . . . . . 271

e) Online Dispute Resolution: zwischen Schiedsgerichtsbarkeit und Mediation

IV. Zivilverfassung: Konstitutionalisierung verbraucherschützender Zivilregimes

1. Verbraucherschiedsgerichtsbarkeit: "Consumer Due Process Protocol" $\operatorname{der} A A A$

2. Online-Streitschlichtung: ABA Best Practices und $i$-ADR-Center . .

3. Trustmark of Trustmarks: Mindeststandards hybrider Organisationen

4. Staatliches Soft-Law und Infrastruktur: EG-Empfehlungen und EEJNet . . . . . . . . . . . . . . . . . . . . . . . . .

5. Staatliche Anreize und Akkreditierung verbraucherschützender Zivilregimes

V. Verbraucherschutz im Wettbewerb transnationaler Zivilregimes: ein Ausblick

\section{Einleitung}

Indem das Internet als Infrastruktur die Transaktionskosten grenzüberschreitender Kommunikation radikal senkt, wirkt es als Katalysator der Globalisierung der Gesellschaft ${ }^{1}$. Rechtskollisionen erhalten hierdurch in allen gesellschaftlichen Bereichen eine gesteigerte Bedeutung ${ }^{2}$. Im Rahmen der allgemeinen Debatte um die Etablierung einer Global Governance kommt der Internetgovernance deshalb eine paradigmatische Rolle $\mathrm{zu}^{3}$. Aus ökono-

1 Engel, Das Internet und der Nationalstaat, in: Dicke u.a., Völkerrecht und Internationales Privatrecht in einem sich globalisierenden internationalen System, Auswirkungen der Entstaatlichung transnationaler Rechtsbeziehungen (2000) 353ff.(BerDGesVölkR, 39); Calliess, Globale Kommunikation - staatenloses Recht, in: Globalisierung als Problem von Gerechtigkeit und Steuerungsfähigkeit des Rechts, hrsg. von Anderheiden/Huster/Kirste (2001) $61 \mathrm{ff}$. (64ff.) (ARSP Beiheft, 79) (zitiert: Globale Kommunikation).

2 Mankowski, Das Internet im Internationalen Vertrags- und Deliktsrecht: RabelsZ 63 (1999) 203ff.; Holznagel/Werle, Sectors and Strategies of Global Communications Regulation: ZRechtssoziol. 2002, $3 \mathrm{ff}$.

3 Vgl. jüngst umfassend Deutscher Bundestag, Globalisierung der Weltwirtschaft, Schlussbericht der Enquete-Kommission (2002) Teil10 (S. $415 \mathrm{ff}$.) zu Global Governance sowie Teil $5 \mathrm{zu}$ Wissensgesellschaft und Internet (insbesondere S. 278ff. zu Internet und Recht); 
mischer Sicht steht dabei die Schaffung eines Rechtsrahmens für den globalen E-Commerce im Vordergrund ${ }^{4}$. Im Hinblick auf eine innovationsoffene Regulierung erscheint es in diesem Zusammenhang als reizvoll, der Frage nach einem Rechtsrahmen für den grenzüberschreitenden Business-to-Consumer-E-Commerce nachzugehen. Denn das deutsche und europäische Verbrauchervertragsrecht stehen aktuell eher für eine gegenläufige Tendenz zur Begrenzung der Privatautonomie zugunsten zwingender Vorgaben des Gesetzgebers, die auch kollisionsrechtlich gegen eine parteiautonome Rechtswahl abgesichert werden ${ }^{5}$. Während etwa das in der E-Commerce-Richtlinie $^{6}$ verankerte Herkunftsstaatprinzip nicht nur das Wirtschaftsaufsichtsrecht, sondern auch weite Teile des Zivilrechts den Innovationskräften des Systemwettbewerbs öffnet, scheint sich das Verbrauchervertragsrecht aufgrund seines Schutzzweckes als mit innovationsoffenen Regulierungsmodellen inkompatibel zu erweisen ${ }^{7}$.

Ist damit auf dem Gebiet des Verbrauchervertragsrechts nicht nur der traditionelle Wettbewerb der individuellen Vertragsklauseln sowie der Klauselwerke (AGB) innerhalb einer staatlichen Privatrechtsordnung, sondern auch der institutionelle Wettbewerb zwischen den Verbraucherschutzmodellen der verschiedenen staatlichen Privatrechtsordnungen ausgeschlossen, so verbleibt als potentieller Innovationsspeicher nur der Raum der gesellschaftlichen Selbstregulierung jenseits des (staatlichen) Rechts. Vor diesem Hintergrund wird im folgenden untersucht, ob und inwieweit sich aufgrund der spezifischen Charakteristika der Internetkommunikation im Bereich des globalen

Beck, Macht und Gegenmacht im globalen Zeitalter (2002); Grewlich, Governance im Cyberspace - Regulierung globaler Netze im Systemwettbewerb?: RIW 2000, 337-345; Engel, The Role of Law in the Governance of the Internet (2002) (Preprints aus der MaxPlanck-Projektgruppe Recht der Gemeinschaftsgüter, 2002/13).

${ }^{4}$ Vgl. die Beiträge in: E-Commerce und Wirtschaftspolitik, hrsg. von Donges/Mai (2001); sowie den Überblick bei Schorkopf, An International Regime of Electronic Commerce?: ZRechtssoziol. 2002, 79ff.

5 Zur Entwicklung des deutschen und europäischen Verbrauchervertragsrechts siehe nur den Überblick in: Münchener Kommentar zum BGB(-Micklitz) I ${ }^{4}(2000)$ Vor $\$ \$ 13$, 14; zur kollisionsrechtlichen Absicherung über Art. 5 EVÜ vgl. nur Nemeth, Kollisionsrechtlicher Verbraucherschutz in Europa (2000); Klauer, Das europäische Kollisionsrecht der Verbraucherverträge zwischen Römer EVÜ und EG-Richtlinien (2002); Staudinger (-Magnus), Kommentar zum BGB ${ }^{13}$, EGBGB/IPR (2002) Art. 29, 29a EGBGB.

6 Richtlinie 2000/31/EG, ABl. EG 2000 L 178/1.

7 Vgl. nur Spindler, Herkunftslandprinzip und Kollisionsrecht-Binnenmarktintegration ohne Harmonisierung?: RabelsZ 66 (2002) 633 ff. (685ff.) (zur Herausnahme des vertraglichen Verbraucherschutzes aus dem Anwendungsbereich des Herkunftslandprinzips); vgl. auch Mankowski, Das Herkunftslandprinzip des E-Commerce-Rechts als Internationales Privatrecht: EWS 2002, 401ff.; zur Innovationsfunktion eines institutionellen Wettbewerbs der Privatrechtsordnungen und zu dessen Voraussetzungen sowie zu deren Fehlen auf dem Gebiet des Verbrauchervertragsrechts siehe Kieninger, Rechtsentwicklung im Wettbewerb der Rechtsordnungen, in: Vereinheitlichung und Diversität des Zivilrechts in transnationalen Wirtschaftsräumen, hrsg. von Ott/Schäfer (2002) 72ff. (99). 
E-Commerce eine Verdichtung von Phänomenen der privaten Normsetzung und der sozialen Selbstregulierung beobachten läßt, die als Emergenz eines transnationalen Verbrauchervertragsrechts interpretiert werden kann.

Zunächst soll dabei eine Definition transnationalen Rechts entwickelt werden, die diesen Begriff an die spontanen Innovationskräfte der globalen Zivil(rechts)gesellschaft koppelt (II.). In einem zweiten Schritt werden dann Entstehungsbedingungen und Phänomene eines transnationalen Verbrauchervertragsrechts beleuchtet (III.). Sodann wird der Frage nach einer Konstitutionalisierung des transnationalen Verbrauchervertragsrechts nachgegangen (IV.). Der Beitrag schließt mit einem Ausblick auf potentielle Ziele und Methoden der Regulierung des Wettbewerbs transnationaler Verbraucherschutzregimes (V.).

\section{Was ist transnationales Recht?}

Im Kontext der Globalisierungsdebatte, die in den vergangenen Jahren auch die Rechtswissenschaft erreicht hat, ist es in Mode gekommen, von transnationalem Recht zu sprechen, wobei sich der Begriff durch eine erhebliche Unschärfe auszeichnet und selten definiert wird. Im folgenden werden zunächst einige aktuelle Verwendungskontexte des Begriffs aufgezeigt, und es wird untersucht, ob diesem gegenüber den etablierten Begriffen des nationalen, internationalen und supranationalen Rechts eine eigenständige Bedeutung zukommt.

1. Die klassische Begriffsdichotomie: nationales und internationales Recht

Im Gefolge der Entstehung des modernen Territorialstaats hat sich eine Tradition des "rechtsphilosophischen Etatismus" etabliert, die einen notwendigen Zusammenhang zwischen Recht und Staat postuliert ${ }^{8}$. "Recht" bezeichnet danach ein nationales Rechtssystem, in welchem jede Form von Rechtsetzung letztlich durch den nationalen Souverän legitimiert wird und Rechtsanwendung den staatlichen Gerichten obliegt. Historisch betrachtet stellt die Durchsetzung des staatlichen Gewaltmonopols gegenüber dem kirchlichen, imperialen und lokalen Gewaltenpluralismus des Mittelalters eine zivilisatorische Errungenschaft dar, auf deren Grundlage die Errichtung des demokratischen Verfassungsstaates überhaupt erst möglich wurde. Der absolutistische Herrschaftsanspruch des Territorialstaats wendet sich freilich

${ }^{8}$ Vgl. nur Kähler, Abschied vom rechtsphilosophischen Etatismus, Besteht ein notwendiger Zusammenhang zwischen Recht und Staat?, in: Der Staat der Zukunft, hrsg. von Calliess/Mahlmann (2002) 69ff. (ARSP Beiheft, 83). 
nicht nur nach innen, wo private Rechtsetzung nur noch aufgrund staatlicher Anerkennung und Autorisierung denkbar ist ${ }^{9}$, sondern auch nach außen. Sachverhalte mit Verbindung zu mehreren Staaten werden durch das internationale Recht geregelt.

Als Völkerrecht (Public International Law oder Law of Nations) werden jene Normen bezeichnet, die vornehmlich die Rechte der Nationalstaaten in ihrer Beziehung untereinander sowie sukzessive die Rechte internationaler Organisationen und erst neuerdings auch die Rechte von Individuen gegenüber dem Staat ${ }^{10}$ - soweit völkerrechtliche Aspekte betroffen sind - regeln. Das Völkerrecht basiert auf internationalen Staatsverträgen als positivem Recht, zudem auf den ungeschriebenen Regeln des Völkergewohnheitsrechts und auf allgemeinen Rechtsprinzipien, insofern diese von den teilnehmenden Nationen allgemein als verbindlich anerkannt werden und insoweit diese sich in den Entscheidungen internationaler Tribunale niederschlagen oder (in Europa) von der herrschenden Rechtslehre anerkannt werden ${ }^{11}$. Als Internationales Privatrecht (Private International Law oder treffender Conflict of Laws) werden demgegenüber jene - abgesehen von einigen Staatsverträgen zu dessen Harmonisierung (z.B. das EVÜ) ${ }^{12}$ oder zur Begründung von internationalem Einheitsrecht (z.B. das Wiener UN-Kaufrecht [CISG] $)^{13}-$ im wesentlichen nationalen Rechtsregeln bezeichnet, nach denen entschieden wird, welches von mehreren nationalen Privatrechten auf grenzüberschreitende Sachverhalte Anwendung findet ${ }^{14}$.

Recht ist demnach entweder als nationales Recht innerstaatliches Recht oder als internationales Recht zwischenstaatliches Recht. In dieser Begriffsdichotomie wird folglich eher der politische Wettbewerb zwischen souveränen Nationalstaaten als die im Kontext der Globalisierung zunehmende gegenseitige Interdependenz betont.

9 F. Kirchhof, Private Rechtssetzung (1987) 138ff.; Busche, Privatautonomie und Kontrahierungszwang (1999) \$2 mit umfangreichen Nachweisen zur Lehre der staatlichen Anerkennung der Privatautonomie in der staatlichen Privatrechtsordnung.

${ }^{10}$ Vgl. Zumbansen, Die vergangene Zukunft des Völkerrechts: Krit. Justiz 2001, 46ff.; Hochhuth, Staatsräson - Geldräson - Menschenräson, Die Selbstpreisgabe des Staates, besonders im Völkerrecht, und wem sie nützt, in: Der Staat der Zukunft (oben N. 8) 85ff.

11 Zu Begriff und Entwicklung des Völkerrechts vgl. Verdross/Simma, Universelles Völkerrecht $^{3}$ (1984) 1-7; Ipsen, Völkerrecht ${ }^{4}$ (1999) 1ff.; Seidl-Hohenveldern/Stein, Völkerrecht $^{10}$ (2000) 1, 12ff. (zur Abgrenzung von verwandten Begriffen).

12 Übereinkommen von Rom über das auf vertragliche Schuldverhältnisse anzuwendende Recht vom 19.6. 1980 (konsolidierte Fassung), ABl. EG 1998 C 27/34; Czernich/ Heiss, EVÜ, Kommentar (1999).

13 Vgl. Schlechtriem, Kommentar zum Einheitlichen UN-Kaufrecht - CISG ${ }^{3}$ (2000) (zitiert: Schlechtriem[-Bearb.]); im Internet abrufbar unter $<w w w . u n i l e x . i n f o>$.

14 Siehe Kegel/Schurig, Internationales Privatrecht ${ }^{8}$ (2000) 4-24 (zum Begriff und seiner Abgrenzung zum Völkerrecht) 69ff. (zu Rechtsangleichung und Einheitsrecht); Kropholler, Internationales Privatrecht ${ }^{4}(2001)$ S $\$ 1,8,9,12$. 
2. Europarecht als supranationales Recht

Die Europäische Union (EU) ist eine durch völkervertragsrechtlichen Gründungsakt geschaffene internationale Organisation, die sich aus dem Kreis der übrigen internationalen Organisationen durch eine Reihe von Besonderheiten, namentlich durch unabhängige Gemeinschaftsinstitutionen, das Mehrheitsprinzip sowie den Vorrang und die unmittelbare Anwendbarkeit des Gemeinschaftsrechts, heraushebt. Auch nach Gründung der Europäischen Union ist damit aber noch kein (Bundes-)Staat im herkömmlichen völkerrechtlichen Sinne geschaffen. Zur Kennzeichnung des überstaatlichen Status eines Europarechts, das im Prozeß der »Verwirklichung einer immer engeren Union« (Art. 1 II EU) nicht mehr klassisches zwischenstaatliches Recht und noch nicht innerstaatliches Recht ist, hat sich daher der Begriff des supranationalen Rechts eingebürgert ${ }^{15}$.

\section{Der neue Transnationalismus: einige Bedeutungskontexte}

Im Gegensatz zu »inter" (zwischen) und »supra (über) ist die Präposition "trans" relativ vieldeutig. Je nach Kontext hat sie u.a. folgende Bedeutungen: über, hinüber, darüber hinaus, jenseits, durch, hindurch, über ... hinweg etc. ${ }^{16}$. Transnational kann als Adjektiv demnach solchen Phänomenen zugeordnet werden, die über den Nationalstaat hinaus, jenseits des Nationalstaats, über dessen Grenzen hinweg und durch Grenzen hindurch wirken. Zur Verdeutlichung ein Beispiel aus der Globalisierungsdebatte: Wurden die global player der Weltwirtschaft zunächst als multinationale Unternehmen bezeichnet und kritisiert (die "Multis"), so setzte sich später der Begriff des transnationalen Unternehmens durch, um deren zunehmende Unabhängigkeit von den Nationalstaaten zu kennzeichnen (nicht vielstaatlich, sondern jenseits der Staaten $)^{17}$. Im Zusammenhang mit Recht können cum grano salis drei Bedeutungskontexte festgemacht werden.

a) Der funktionalistische Ansatz: Norm vs. Sachverhalt

Der Begriff des transnationalen Rechts wurde - soweit ersichtlich - erstmals durch den Richter am Internationalen Gerichtshof (IGH) Phillip C. Jes-

15 C. Calliess/Ruffert(-Wichard), Kommentar des Vertrages über die Europäische Union und des Vertrages zur Gründung der Europäischen Gemeinschaft ${ }^{2}$, EUV/EGV (2002) Art. 1 EGV Rz. 2; dies.(-Calliess), ebd. Art. 1 EUV Rz. 8, 19 mit weiteren Nachweisen.

${ }_{16} \mathrm{Vgl}$. etwa die unterschiedlichen Bedeutungsgehalte in den Wörtern Transport, Transit, transalpin, transatlantisch, transkulturell, translation. Siehe die Angaben im »Duden« und im »Kleinen Stowasser« werden die oben genannten Bedeutungskontexte genannt.

17 Während die OECD vom multinational enterprise spricht (vgl. die OECD Guidelines for Multinational Enterprises, erhältlich unter $<$ www.oecd.org $>$ ), verwendet die 
sup in die juristische Diskussion eingeführt ${ }^{18}$. Transnationales Recht ist danach ein Sammelbegriff für all jene Normen, die Handlungen oder Ereignisse regeln, die nationale Grenzen transzendieren. Erfaßt sind straf-, zivil- und öffentlich-rechtliche Aspekte, Völkerrecht und Internationales Privatrecht. Transnationale Sachverhalte involvieren zudem nicht nur Staaten, sondern auch Individuen, Unternehmen und andere Gruppen. Diese Definition stellt im wesentlichen eine Erweiterung des Begriffs des internationalen (Völker-) Rechts dar, indem aus funktionaler Perspektive alle grenzüberschreitenden Sachverhalte erfaßt werden und die Bedeutung privater Akteure in einer globalisierten Welt betont wird. Eine Reihe von US-amerikanischen juristischen Zeitschriften, die sich diesem Konzept verschrieben haben, veröffentlichen dementsprechend Artikel zu allen privaten und öffentlichen Aspekten des internationalen Rechts und der Rechtsvergleichung ${ }^{19}$.

Dieser weite, unspezifisch auf grenzüberschreitende Phänomene rekurrierende Begriff des transnationalen Rechts ist im Kontext der zunehmenden globalen Interdependenz recht populär geworden und wird auch im Zusammenhang mit der extraterritorialen Wirkung von nationalen Rechtsakten gebraucht, etwa wenn im Zuge der gegenseitigen Anerkennung im europäischen Verwaltungsrecht von transnationalen Verwaltungsakten gesprochen wird $^{20}$. Er konnte sich allerdings in der juristischen Dogmatik des Völkerrechts und des IPR nicht durchsetzen ${ }^{21}$. Der Grund hierfür liegt darin, daß es nicht das Recht ist, das im Hinblick auf seine Quellen oder seinen Geltungsanspruch transnational ist, sondern daß lediglich die geregelten Sachverhalte grenzüberschreitend $\operatorname{sind}^{22}$. Damit sind die erfaßten Normenkomplexe aber

UNCTAD in ihrem World Investment Report seit 1998 den Begriff der "Transnational Corporation" (TNC); vgl. Heins, Der neue Transnationalismus (2001) 93.

18 Jessup, Transnational Law (1956) 2f.; dazu Slaughter, Breaking out, The Proliferation of Actors in the International System, in: Global Prescriptions, hrsg. von Garth/Dezelay (2002) $12 \mathrm{ff}$.

19 Vanderbilt Journal of Transnational Law < http://law.vanderbilt.edu/journal/history.html $>$; Columbia Journal of Transnational Law $<\mathrm{www} \cdot$ columbia.edu/cu/jtl/ $>$; Journal of Transnational Law \& Policy <www.law.fsu.edu/journals/transnational $>$; Transnational Law \& Contemporary Problems $<$ www.uiowa.edu/ $>$.

${ }^{20}$ Vgl. etwa Ruffert, Der Transnationale Verwaltungsakt: Verw. 34 (2001) 453-485 mit weiteren Nachweisen, der darunter im wesentlichen Verwaltungsakte mit grenzüberschreitender Wirkung versteht. Ein wichtiges Beispiel ist die extraterritoriale Anwendung des Kartellrechts, etwa wenn die EG-Kommission amerikanische Unternehmenszusammenschlüsse kontrolliert, weil diese sich in der EG auswirken.

21 Siehe Seidl-Hohenveldern/Stein (oben N.11) 14; Kegel/Schurig 23; Kropholler 95 (beide oben N.14).

22 Siehe dazu Horn, The Use of Transnational Law in the Contract Law of International Trade and Finance, in: The Practice of Transnational Law 67ff., der den Begriff des transnationalen Rechts deshalb auf transnationale Rechtsquellen beschränken will, womit nationales Recht ausgeschlossen wird, andererseits der klassische Begriff des Völkerrechts aber um privatautonom geschaffene transnationale Normen erweitert wird. 
zu vielfältig, um das Konzept für die dogmatische Diskussion anschlußfähig zu machen.

\section{b) Der kulturkritische Ansatz: Multilateralismus vs. Unilateralismus}

Eine andere Verwendung des Begriffs des transnationalen Rechts knüpft in gewisser Weise gerade an das Fehlen transnationaler Rechtsquellen an. Transnationales Recht ist danach ein Recht, das zwar globale Geltung beansprucht, aber nicht aus den globalen Rechtsquellen des völkerrechtlichen Multilateralismus legitimiert ist, sondern eher auf einer unilateralen Ausdehnung bzw. extraterritorialen Anwendung der Maßstäbe und Prinzipien der OECD-Staaten (z.B. general principles of the laws of civilized nations) beruht $^{23}$.

Diese Deutung schließt an eine Beobachtung von Samuel Huntington aus dem Jahre 1973 an, wonach insbesondere US-amerikanische Organisationen und Firmen durch eine globale Ausdehnung ihres Handlungsradius westliche Kulturmaßstäbe (also auch Rechtsvorstellungen) über die nichtstaatlichen Sphären in die Entwicklungsländer exportieren ${ }^{24}$, und der nach dem Fall des Eisernen Vorhangs seine berühmte These aufstellte, daß dieser einseitige Kulturimperialismus zu einem Kampf der Kulturen führen werde ${ }^{25}$. Aus dieser Sicht ist die im Rahmen der Globalisierungsdebatte anzutreffende Rede von einem sich in einer globalen Zivilgesellschaft formierenden "globalen Recht" jenseits der Nationalstaaten ${ }^{26} \mathrm{zu}$ vorschnell, worauf mit dem Begriff des transnationalen Rechts hingewiesen werden soll.

23 Die Frage ist dann, welche Staaten als civilized nations gelten. Völkerrechtlich sind damit zwar grundsätzlich alle Mitglieder der Vereinten Nationen gemeint, die These ist aber, daß sich allgemeine Rechtsprinzipien faktisch als unilaterale Generalisierung der westlichen Rechtstradition darstellen. Für eine Verwendung des Begriffs transnationalen Rechts in diesem kulturkritischen Sinne vgl. etwa Günther, Rechtspluralismus und universaler Code der Legalität: Globalisierung als rechtstheoretisches Problem, in: Die Öffentlichkeit der Vernunft und die Vernunft der Öffentlichkeit, FS Habermas (2001) 539ff.

${ }^{24}$ Huntington, Transnational Organizations in World Politics: World Politics 25 (1973) $333 \mathrm{ff}$. (344): "Transnationalism is the American mode of expansion.» Gemeint ist in Abgrenzung zum Multilateralismus der UNO einerseits und zum europäischen Kolonialismus andererseits die Fähigkeit, Entscheidungen mit Auswirkungen für andere Länder ohne deren politische Zustimmung zu treffen, aber auch ohne diese Länder politisch zu unterwerfen, also eine Art Unterwanderung im nichtstaatlichen Bereich.

${ }_{25}$ Huntington, The Clash of Civilisations and the Remaking of World-Order (1996); vgl. im einzelnen die Darstellung der soziologischen und politologischen Debatte bei Heins (oben N.17) $18 \mathrm{ff}$.

26 Vgl. etwa Global Law Without a State, hrsg. von Teubner (1997). 
c) Der post-etatistische Ansatz: staatliches vs. selbstgeschaffenes Recht

Demgegenüber wird der Begriff des transnationalen Rechts im Kontext des internationalen Handelsrechts in einem anderen, wesentlich spezifischeren Sinne verwendet: transnationales (Handels-)Recht bezeichnet hier eine dritte Kategorie von Recht jenseits der traditionellen Dichotomie von nationalem und internationalem Recht ${ }^{27}$. Gemeint ist die neue lex mercatoria (New Law Merchant) als autonomes Rechtssystem jenseits des Nationalstaats, das sich auf allgemeine Rechtsprinzipien, d.h. im Wege der funktionalen Rechtsvergleichung aus dem Common Core der nationalen Privatrechtssysteme abgeleitete Grundregeln (z.B. die UNIDROIT Principles of International Commercial Contracts oder die Lando Principles of European Contract Law) ${ }^{28}$, sowie auf die Handelsbräuche und Gewohnheiten der internationalen Kaufmannschaft (z.B. standardisierte Vertragsbedingungen wie die Incoterms der ICC oder Formularverträge und Allgemeine Geschäftsbedingungen) ${ }^{29}$ gründet, und dessen Anwendung, Interpretation und Fortbildung in den Händen der internationalen Schiedsgerichtsbarkeit liegt ${ }^{30}$.

27 Berger, The Creeping Codification of the lex mercatoria (1999) 40, $42 \mathrm{f}$. Nicht alle Befürworter einer neuen lex mercatoria vertreten einen derart dezidiert nichtstaatlichen Begriff des transnationalen Rechts: vgl. Horn (oben N. 22) 67f., der neben Privatkodifikationen und allgemeinen Rechtsprinzipien auch völkerrechtliche Übereinkommen wie das CISG und supranationales EG-Primärecht einbezieht.

28 Vgl. Bonell, The UNIDROIT Principles and Transnational Law, in: The Practice of Transnational Law 23-41, der transnationales Recht definiert als "all kinds of principles and rules of non-national or a-national character used in international business practice as an alternative to domestic law« (a.a.O. 23); Michaels, Privatautonomie und Privatkodifikation, $\mathrm{Zu}$ Anwendbarkeit und Geltung allgemeiner Vertragsrechtsprinzipien: RabelsZ 62 (1998) 580ff.; Berger, Einheitliche Rechtsstrukturen durch außergesetzliche Rechtsvereinheitlichung: JZ 1999, 369ff.; Blase, Die Grundregeln des Europäischen Vertragsrechts als Recht grenzüberschreitender Verträge (2001). Eine Datenbank zum transnationalen Recht, die neben den Prinzipien- und Regellisten auch Schiedssprüche in Bezug nimmt, findet sich unter $<$ www.tldb.de $>$.

29 Garro, Rule-Setting by Private Organizations, Standardization of Contracts, and the Harmonization of International Sales Law, in: Foundations and Perspectives of International Trade Law, hrsg. von Fletcher/Mistelis/Cremona (2001) $310 \mathrm{ff.}$

${ }^{30}$ Derains, Transnational Law in ICC Arbitration, in: The Practice of Transnational Law 43ff., der darlegt, unter welchen Bedingungen Schiedsgerichte nach den ICC Arbitration Rules transnationales (d.h. nicht-nationales) Recht anwenden (bzw. »schaffen«), und daß die resultierenden Schiedssprüche vollstreckbar sind. Gaillard, Transnational Law, A legal system or a method of decision-making?, in: The Practice of Transnational Law $53 \mathrm{ff}$. wendet ein, daß die Kodifizierung allgemeiner Rechtsprinzipien in den erwähnten Listen (oben N.28) immer unvollständig bleiben muß und betont, daß die Anwendung/Findung transnationaler Regeln der lex mercatoria durch Schiedsrichter vor allem auf einer rechtsvergleichenden Methode (comparative approach) beruht, wodurch der rechtsschöpfende Charakter der Schiedsgerichtsbarkeit betont wird: "In sum [...] the list approach and, even more certainly, the comparative law approach to transnational rules perform quite well as far as completeness, structured character, evolving nature or predictability standards are concerned. As a result, if not a genuine legal order, transnational rules do perform [...] a 
Diese neue lex mercatoria ist sicherlich das prominenteste Beispiel für ein (privat-)autonomes transnationales Rechtssystem ${ }^{31}$. Die Idee einer dritten Kategorie eines transnationalen Rechts jenseits des Nationalstaats läßt sich freilich verallgemeinern, insofern sich auf globaler Ebene die Entstehung einer Vielzahl von spontanen oder formalisierten, privaten oder hybriden transnationalen Rechtsregimes beobachten läßt ${ }^{32}$. Neben der lex mercatoria ist die Uniform Domain Name Dispute Resolution Policy (UDRP) der Internet Corporations for Assigned Names and Numbers (ICANN) ein gegenwärtig vieldiskutiertes Beispiel ${ }^{33}$; dem Konzept transnationaler Rechtsregimes kommt im Rahmen der Debatte um eine Global Governance freilich generell eine hohe Bedeutung $\mathrm{zu}^{34}$. Solche Rechtsregimes entwickeln sich als »functional, overlapping, and competing jurisdictions $\$^{35}$ um konkrete Problemlagen in den funktional ausdiffernzierten gesellschaftlichen Teilsystemen herum, d.h. ihre Entstehung ist punktuell, problembezogen und konfliktgetrieben. Der resultierende transnationale Rechtspluralismus ${ }^{36}$ kann als Ergebnis des

function strikingly similar to that of a genuine legal system« (a.a.O. 65). Demgegenüber weist Juenger, Some random remarks from overseas, in: The Practice of Transnational Law $81 \mathrm{ff}$, darauf hin, daß im anglo-amerikanischen Common-Law-System transnationale Regeln als allgemeine Rechtsprinzipien auch von staatlichen Gerichten angewendet werden können: "American law, like a sponge, can soak up almost anything that is worthwhile [...] « (a.a.O. 87).

31 Für eine empirische Studie zur praktischen Bedeutung der lex mercatoria vgl. Berger u.a., The CENTRAL enquiry on the use of transnational law in international contract law and arbitration, in: The Practice of Transnational Law $91 \mathrm{ff}$. mit dem Ergebnis, daß transnationales Recht im internationalen Handelsverkehr zwar genutzt wird, daß die Kenntnis von seiner Existenz und seinem Inhalt jedoch ungenügend ist (a.a.O. 112f.) Ein ausführlicher Überblick über die Debatte der vergangenen 40 Jahre zur lex mercatoria findet sich bei Berger, The New Law Merchant and the Global Market Place, in: The Practice of Transnational Law 1-22; Vgl. auch Zumbansen, Piercing the Legal Veil: Commercial Arbitration and Transnational Law: Eur. L. J. 8 (2002) 400ff., jeweils mit weiteren Nachweisen.

32 Teubner, Privatregimes: Neospontanes Recht und duale Sozialverfassungen in der Weltgesellschaft, in: Zur Autonomie des Individuums, FS Spiros Simitis (2000) $437 \mathrm{ff}$.

33 Vgl. nur Lehmkuhl, The Resolution of Domain Names vs. Trademark Conflicts, A Case Study on the Regulation Beyond the Nation State: ZRechtssoziol. 2002, 61ff.; Calliess, Reflexive Transnational Law 185ff. jeweils mit weiteren Nachweisen.

${ }_{34} \mathrm{Vgl}$. etwa im Kontext von Internet Governance Perritt, Cyberspace Self-Government: Town-Hall Democracy or Rediscovered Royalism: Berkeley Tech. L.J. 12 (1997) 413ff.; ders., The Internet is Changing the Public International Legal System: KY. L. Rev. 88 (2000) 885ff.; Grewlich, Conflict and good Governance in Cyberspace, Multi-level and Multi-actor Constitutionalisation, in: Governance of Global Networks in the Light of Differing Local Values, hrsg. von Engel/Keller (2000) $237 \mathrm{ff}$.

35 Die Idee der FOCI wurde entwickelt von Frey/Eichenberger, The New Democratic Federalism for Europe (1999).

36 Teubner, Global Bukowina: Legal Pluralism in the World Society, in: Global Law Without a State (oben N.26) 3-28; K. v. Benda-Beckmann, Transnational Dimensions of Legal Pluralism, in: Begegnung und Konflikt, Eine kulturanthropologische Bestandsaufnahme, hrsg. von W. Fikentscher (2001) 33-48; dies., Globalization and legal pluralism: International Law FORUM du droit international 4 (2002) 19-25. 
normativen Vakuums verstanden werden, welches sich im klassischen System des nationalen und internationalen Rechts in der Weltgesellschaft ergibt ${ }^{37}$.

\section{Transnationales Recht: eine Definition im Tetralemma des internationalen Rechts}

Definitionen sind stets kontext- und zweckbezogen. Ohne den Wert der funktionalen oder kulturkritischen Verwendungsweisen des Begriffs des transnationalen Rechts generell in Zweifel zu ziehen, erscheinen diese für eine Verwendung im rechtsdogmatischen Kontext jedoch als zu unspezifisch, weil es an eindeutigen Abgrenzungskriterien gegenüber den etablierten Begriffen des nationalen, internationalen und supranationalen Rechts fehlt. Demgegenüber umschreibt der post-etatistische Ansatz ein Rechtsphänomen, dessen kategorialer Unterscheidungswert anhand der logischen Figur des Tetralemma erläutert werden kann. Danach können in bezug auf jede denkbare Unterscheidung grundsätzlich vier Positionen eingenommen werden, nämlich zunächst die beiden Seiten der Unterscheidung (»das eine«, »das andere «), sodann eine dritte Position, die die Grenze der Unterscheidung durch Kompromisse verwischt ("sowohl als auch") und schließlich eine vierte Position, die die Maßgeblichkeit der Unterscheidung in Frage stellt ("weder noch $)^{38}$. Im Tetralemma der klassischen Unterscheidung zwischen nationalem und internationalem Recht wird die dritte Position durch den Begriff des supranationalen Rechts belegt, während für einen eigenständigen Begriff transnationalen Rechts die vierte Position offensteht. Transnationales Recht ist dann weder nationales noch internationales Recht, und auch nicht ein supranationales Mittelding, sondern eine dritte Kategorie jenseits des staatlichen Rechts.

Für die rechtstheoretische, verfassungs- und privatrechtsdogmatische Debatte $^{39}$ um neue Rechtsphänomene in einer zunehmend globalisierten Welt möchte ich deshalb folgende Definition vorschlagen:

Transnationales Recht bezeichnet eine dritte Kategorie von autonomen Rechtssystemen jenseits der traditionellen Kategorien des staatlichen nationalen und internationalen Rechts. Transnationales Recht wird durch die

37 Berger (oben N.31) 14; Calliess, Globale Kommunikation (oben N. 1).

38 Zur Denkfigur des Tetralemma und seiner Anwendung auf den Begriff des Rechts vgl. Calliess, Das Tetralemma des Rechts: ZRechtssoziol. 2000, 293 ff. mit weiteren Nachweisen.

39 Vgl. nur die Beiträge in: Dicke u.a.; Globalisierung als Problem von Gerechtigkeit und Steuerungsfähigkeit des Rechts (beides oben N.1); Schwerpunktheft "Transnationales Recht", hrsg. von Albert/Lehmkuhl: ZRechtssoziol. 23 (2002) Heft 2; Die Privatisierung des Privatrechts, rechtliche Gestaltung ohne staatlichen Zwang, Heidelberger Tagung 4.7. 9. 2002: Jb. Junger Zivilrechtswiss. 2002 (2003) $1 \mathrm{ff}$. 
Rechtsschöpfungskräfte einer globalen Zivilgesellschaft geschaffen und entwickelt, es ist auf allgemeine Rechtsprinzipien und deren Kondensation und Konfirmation in gesellschaftlicher Praxis (Übung) gegründet, seine Anwendung, Interpretation und Fortbildung obliegt - jedenfalls vornehmlich - privaten Anbietern alternativer Streitschlichtungsmechanismen, und eine Kodifikation findet - wenn überhaupt - in Form von allgemeinen Prinzipien- und Regelkatalogen, standardisierten Vertragsformularen oder Verhaltenskodizes statt, die von privaten Normierungsinstitutionen aufgestellt werden.

\section{Transnationales Verbrauchervertragsrecht}

Auf der Grundlage dieser Definition kann zunächst bestimmt werden, worauf sich der Blick im folgenden zu richten hat. Ein transnationales Verbrauchervertragsrecht bezeichnet - wenn es denn existiert - ein nichtstaatliches Recht der grenzüberschreitenden Verbraucherverträge, welches die in einer relevanten gesellschaftlichen Praxis des Abschlusses solcher Verträge angelegte Nachfrage nach Rechtssicherheit und Rechtsschutz durch private Normierungen und deren Anwendung in alternativen Verfahren der Streitschlichtung befriedigt.

In dieser Begriffsbestimmung ist bereits die These angelegt, daß die Entstehung transnationaler Rechtssysteme an bestimmte gesellschaftliche Entstehungsbedingungen gebunden ist, die genauer beleuchtet werden sollen (1.), bevor die emergenten Phänomene eines transnationalen Verbrauchervertragsrechts untersucht werden können (2.).

\section{Rechtliche und soziale Entstehungsbedingungen} transnationalen Rechts

Staatliche Rechtsordnungen fußen auf dem Gewaltmonopol des Nationalstaats und können deshalb auch an den Bedürfnissen der gesellschaftlichen Praxis - die in diesem Kontext nicht als Nachfrager, Kunde oder (Rechts-) Verbraucher, sondern unilateral als Rechtsunterworfener und Rechtsadressat in den Blick gerät - vorbei entstehen ${ }^{40}$ und bestehen ${ }^{41}$. Transnationale Rechtssysteme beruhen hingegen auf den Ordnungsleistungen privater oder hybrider

40 So etwa das Ergebnis der Auswertung der Stellungnahmen der Wirtschaft zur Mitteilung der EU-Kommission zum Europäischen Vertragsrecht (KOM 2001[398]) bei Ott/ Schäfer, Die Vereinheitlichung des europäischen Vertragsrechts, Ökonomische Notwendigkeit oder akademisches Interesse, in: Vereinheitlichung und Diversität des Zivilrechts in transnationalen Wirtschaftsräumen (oben N. 7) $203 \mathrm{ff}$.

${ }_{41}$ Das ist der Ausgangspunkt der ökonomischen Analyse des Rechts, vgl. nur Eidenmüller, Effizienz als Rechtsprinzip (1995). 
Normunternehmer und Streitschlichter, die sich als Dienstleister mit Aussicht auf Erfolg nur etablieren können, wenn ihr Angebot nicht an den Bedürfnissen des Marktes vorbeigeht und es im Wettbewerb mit anderen Angeboten bestehen kann (Merchants of Law as Moral Entrepreneurs) ${ }^{42}$. Zu den rechtssoziologischen Entstehungsbedingungen transnationalen Rechts gehört also erstens, daß im relevanten gesellschaftlichen Bereich überhaupt Nachfrage nach Rechtssicherheit und Streitschlichtung besteht, und daß zweitens diese Nachfrage nicht schon durch andere Angebote befriedigt und der Markt damit gesättigt ist.

Auf das transnationale Verbrauchervertragsrecht bezogen bedeutet dies, daß grenzüberschreitende Verbraucherverträge zum einen in einem Ausmaß Bestandteil der gesellschaftlichen Wirklichkeit sein müssen, das eine hinreichende Nachfrage nach Rechtssicherheit auf diesem Rechtsgebiet begründet. Dabei ist das Augenmerk insbesondere auf Wandlungen in den Außenhandelsstrukturen $\mathrm{zu}$ richten, die ihrerseits durch technische Innovationen wie das Internet oder rechtliche Innovationen wie den Europäischen Binnenmarkt oder die World Trade Organization (WTO) induziert sein können. Zum anderen ist es im Hinblick auf die Wettbewerbssituation von Bedeutung, ob das staatliche Recht der grenzüberschreitenden Verbraucherverträge einen effizienten Rechtsrahmen bietet. Wo das staatliche Recht versagt, entsteht hingegen ein normatives Vakuum, das potentiell durch private Ordnungsdienstleistungen ausgefüllt werden $\mathrm{kann}^{43}$.

Grenzüberschreitende Verbraucherverträge sind ein in tatsächlicher und rechtlicher Hinsicht komplexes Phänomen, das nicht ohne Schwierigkeiten zu definieren ist. Denn schon eine präzise Bestimmung der Begriffsbestandteile, also internationale Verträge einerseits und Verbraucherverträge andererseits, fällt schwer ${ }^{44}$. Zur Abgrenzung des Gegenstandsbereichs dieser Untersuchung soll

42 Vgl. Dezelay/Garth, Dealing in Virtue (1996) Ch. 3 (S.33ff.); zum Konzept des "Norm entrepreneur« vgl. Eric Posner, Law and Social Norms (2000) 29ff. et passim.

${ }_{43}$ Mit dieser sehr verkürzten Darstellung soll keineswegs ein rein funktionalistischer Rechtsbegriff vertreten werden, nach dem es für die Entstehung von Recht generell und ausschließlich nur auf die Begründung von Rechtssicherheit ankäme (zum vom Verfasser vertretenen Rechtsbegriff vgl. Calliess, Prozedurales Recht [1999] mit einer Definition auf S. 180). Im Kontext des neuentdeckten Wettbewerbs justizieller Dienstleistungen (vgl. Hoffmann-Riem, Modernisierung von Recht und Justiz [2001] Kap. 2 und 3) geht es vorliegend allein um die Frage nach den Bedingungen der Emergenz privater Ordnungsleistungen, und hier bieten sowohl die rechtssoziologische Theorie der reflexiven Institutionalisierung (Luhmann, Rechtssoziologie ${ }^{3}$ [1987] Kap. II "Rechtsbildung") als auch die neue Institutionenökonomik (vgl. Ellickson, Order without Law [1991]; Benson, The Enterprise of Law, Justice without the State [1990]) mit ihrem Fokus auf funktionale Äquivalente im und zum Recht reichhaltige, sich ergänzende Analyseinstrumente (vgl. Calliess, Reflexive Transnational Law $185 \mathrm{ff}$. mit weiteren Nachweisen).

${ }_{44}$ Der Begriff des internationalen Vertrages ist im EVÜ und EGBGB nicht definiert, zur Definition vgl. Mäsch, Rechtswahlfreiheit und Verbraucherschutz (1993) 97ff., 98 mit weiteren Nachweisen in N.9. Ein Begriffskern ergibt sich aus Art. 1 CISG, wonach Käufer 
es genügen, einen Begriffskern zu bezeichnen: gemeint sind vornehmlich, aber nicht ausschließlich Verträge über die Lieferung von Waren oder die Erbringung von Dienstleistungen an einen Verbraucher durch einen aus dessen Sicht im Ausland niedergelassenen Unternehmer.

a) Die Ausgangslage: internationales Handelsrecht und nationales Verbraucherrecht

In einer Welt, in der die Menschen ihren persönlichen Bedarf überwiegend regional bei stationären Händlern und Dienstleistern decken, bilden grenzüberschreitende Verbraucherverträge eine Ausnahmeerscheinung ${ }^{45}$. Selbst der Versandhandel ist überwiegend national organisiert ${ }^{46}$. Seitdem der Verbraucherschutzgedanke in das Privatrecht Einzug gehalten hat, werden grenzüberschreitende Verbraucherverträge als schutzbedürftige Situationen erfaßt, insoweit die Gefahr besteht, daß nationale Verbraucherschutzvorschriften durch international-privatrechtliche Gestaltung umgangen werden ${ }^{47}$. Der im internationalen Privat- und Zivilverfahrensrecht verankerte kollisions- und zuständigkeitsrechtliche Verbraucherschutz bestätigt insofern implizit den Ausnahmecharakter grenzüberschreitender Verbraucherverträge.

und Verkäufer in unterschiedlichen Staaten niedergelassen sein müssen, vgl. Schlechtriem (-Ferrari) (oben N.13) CISG Art. 1 Rz. 40ff. Zum Begriff des Verbrauchervertrages vgl. Faber, Elemente verschiedener Verbraucherbegriffe in EG-Richtlinien, zwischenstaatlichen Übereinkommen und nationalem Zivil- und Kollisionsrecht: ZEuP 1998, 854ff.; Calliess, Nach der Schuldrechtsreform: Perspektiven des Verbrauchervertragsrechts: AcP 203 (2003) 575-602.

${ }^{45}$ Von führenden Verbraucherschutzexperten (Christian Joerges unter Zustimmung von Ross Cranston, Hans-Wolfgang Micklitz, Thomas Wilhelmsson) wurde der grenzüberschreitende Verbraucher, der zunehmend im Fokus der Verbraucherschutzpolitik der Europäischen Kommission steht (vgl. "Green Paper on EU Consumer Protection", COM[2001]531 final) auf der Londoner Konferenz der Society of European Contract Law (SECOLA) im Mai 2002 deshalb als "Chimäre" (i.S.v. Hirngespinst) bezeichnet.

${ }^{46}$ Ausländische Versandhäuser werden auf dem deutschen Markt regelmäßig über eine deutsche Zweigniederlassung oder eine deutsche Tochtergesellschaft tätig, also über »Direktinvestitionen", die die Transaktionen rechtlich zu Inlandsgeschäften machen. Vgl. die Ergebnisse einer Mitgliederbefragung der European Mail Order and Distance Selling Trade Association (EMOTA) vom 30.9. $2002<$ www.emota-aevpc.org/>: "Sales to consumers in other states directly across borders are still insignificant (no more than $3 \%$ ) as a part of total sales due to existing barriers. Companies prefer to work together with or acquire a local firm in order to profit from their knowledge of the local market, consumer attitude and interpretation of local legislation ('think international, act local $)$."

${ }_{47}$ Die Ratio des Art 5 EVÜ (= Art. 29 EGBGB) setzt voraus, daß erstens das materielle Privatrecht des Verbraucherlandes überhaupt spezielle Verbraucherschutzvorschriften enthält und daß zweitens das materielle Privatrecht anderer Staaten dieses Schutzniveau potentiell unterschreitet. Vgl. nur Staudinger(-Magnus) (oben N.5) Art. 29 EGBGB Rz.1ff.; Mäsch (oben N. 44) 22ff. 
Der Außenhandel wird in dieser Welt vornehmlich innerhalb der hochspezialisierten Gruppe der internationalen Kaufmannschaft abgewickelt oder zunehmend in multinationalen Unternehmen internalisiert ${ }^{48}$. Mit dem IPR und dem internationalen Zivilverfahrensrecht stellen die nationalen Privatrechtsordnungen freilich einen institutionellen Rahmen für den Welthandel zur Verfügung, der diesen Namen nicht wirklich verdient. Denn die Anwendung des nationalstaatlichen IPR führt zu einer zunehmend als künstlich empfundenen Nationalisierung internationaler Verträge, und das internationale Zivilverfahrensrecht enthält keine befriedigende Regelung der Zuständigkeit sowie der gegenseitigen Anerkennung und Vollstreckung nationaler

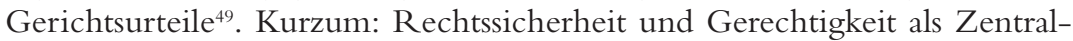
funktionen des Rechts sind nicht gewährleistet.

Angesichts dieser Lage hat der internationale Handel in den vergangenen Jahrzehnten zunehmend die Flucht in die Privatisierung der Streitschlichtung angetreten ${ }^{50}$. Die internationale Schiedsgerichtsbarkeit genießt nicht nur den

48 Zur Funktion von Groß- und Außenhandelsunternehmen, Absatzmittlern und Direktinvestitionen im direkten und indirekten Import/Export vgl. Jahrmann, Außenhandel ${ }^{10}$ (2001) 51-84. In Abhängigkeit von den zugrundeliegenden Definitionen und Daten wird geschätzt, daß zwischen 25\% (vgl. Siebert, Außenwirtschaft ${ }^{7}$ [2000] 129f.) und bis zu 50\% (Beck [oben N.3] 48) des Welthandels als »Intra-Firmen-(Nicht)-Handel« innerhalb der multinationalen/transnationalen Unternehmen abgewickelt wird. Vgl. auch den UNCTAD World Investment Report 2002, Overview: "Recent estimates suggest that there are about 65,000 TNCs (Transnational Corporations) today, with about 850,000 foreign affiliates across the globe [...] (which) account for [...] one-third of world exports. Finally, if we take into account the value of TNCs' non-equity relationships (e.g. international subcontracting, licensing, contract manufacturers) they would account for even larger shares in the global aggregates mentioned above. " $\mathrm{Zu}$ den Problemen der statistischen Erfassung vgl. Globalisierung der Weltwirtschaft (oben N. 3) $132 \mathrm{ff}$.

${ }^{49} \mathrm{Vgl}$. zu diesem, auf ein (nicht notwendig staatliches) materielles Einheitsrecht hin drängenden Standpunkt der »Transnationalisten « Berger, The Creeping Codification of the lex mercatoria (oben N.27) 9ff.; Schmidtchen, Lex mercatoria und die Evolution des Rechts, in: Vereinheitlichung und Diversität des Zivilrechts in transnationalen Wirtschaftsräumen (oben N. 7) 1-31; die »Traditionalisten« halten hingegen eine Harmonisierung des IPR und des Internationalen Zivilprozeßrechts für vorrangig und ausreichend: vgl. nur Mankowski, Wider ein transnationales Cyberlaw: Archiv für Presserecht (AfP) 1999, 138ff. (zitiert: Cyberlaw); Behrends, Die Bedeutung des Kollisionsrechts für die "Globalisierung" der Wirtschaft, in: 75 Jahre Max-Planck-Institut für ausländisches und internationales Privatrecht (2002) $381 \mathrm{ff}$; Sonnenberger, Privatrecht und Internationales Privatrecht im künftigen Europa: Fragen und Perspektiven: RIW 2002, 489ff.; vermittelnd Kronke, Zur Komplementarität von IPR und Einheitsrecht bei der Modernisierung des Wirtschaftsrechts, Eine Fallstudie, in: 75 Jahre Max-Planck-Institut für ausländisches und internationales Privatrecht (diese Note) 757ff. (»kein aut-aut»); sowie Grundmann, Internationales Privatrecht als Verfassungsordnung: RIW 2002, 329ff. ("Europäisches System der Vertragsrechte«).

${ }_{50}$ Berger, The New Law Merchant and the Global Market Place, A 21st Century View of Transnational Commercial Law: Int. Arb. L. Rev. 2000, 91ff.; empirische Belege bei Dezelay/Garth (oben N. 42); Berger u.a., The CENTRAL Enquiry on the Use of Transnational Law (oben N.31) $91 \mathrm{ff}$. 
durch das New Yorker UN-Übereinkommen von 1958 (UNÜ) ${ }^{51}$ begründeten Vorteil der gegenseitigen Anerkennung und Vollstreckung von Schiedssprüchen, sondern zeigt darüber hinaus die Tendenz zu einer Transnationalisierung des Vertragsrechts, zur Herausbildung einer neuen lex mercatoria jenseits der nationalen Privatrechtsordnungen. Die Grundregeln dieses transnationalen Handelsrechts, das sich aus den in der Schiedsgerichtsbarkeit anerkannten allgemeinen Rechtsprinzipien und internationalen Handelsbräuchen speist, sind in sogenannten Privatkodifikationen niedergelegt, die von den Vertragsparteien im Wege der Rechtswahl in Bezug genommen werden können $^{52}$. Diese weitgehende Privatisierung auch des materiellen Vertragsrechts wurde von der internationalen Staatengemeinschaft durch das UNModellgesetz zur internationalen Schiedsgerichtsbarkeit, welches Schiedsgerichten die Anwendung nichtstaatlicher Rechtsregeln erlaubt, rechtlich sanktioniert ${ }^{53}$.

b) Herausforderungen: Europäischer Binnenmarkt und elektronischer Weltmarktplatz

Das so umrissene Gleichgewicht zwischen international zwingendem nationalen Verbrauchervertragsrecht einerseits und transnationalem Handelsrecht andererseits wird gegenwärtig durch zwei Entwicklungen in Frage gestellt, die dem dualen Modell die tatsächliche Basis und damit gleichsam die Geschäftsgrundlage entziehen. Zum einen wird diskutiert, ob die europäische Integration mit der Einführung des Euro nicht ein Niveau erreicht hat, welches im Hinblick auf die Vollendung des Binnenmarktes nach einem einheitlichen europäischen Vertragsrecht verlangt. Ein Europäisches Zivilgesetzbuch träte nicht nur an die Stelle der nationalen Verbrauchervertragsrechte,

51 Text und Ratifikationsstatus der Convention on the Recognition and Enforcement of Foreign Arbitral Awards sind abrufbar unter <www.uncitral.org/en-index.htm $>$.

$52 \mathrm{Vgl}$. die Nachweise oben I. 3 c).

53 Art. 28 I 1 des UNCITRAL Model Law on International Commercial Arbitration, erhältlich unter <www.uncitral.org/en-index.htm>, erklärt die von den Parteien gewählten "rules of law « für anwendbar (= \$1051 I 1 ZPO »Rechtsvorschriften« im Gegensatz zu Art. 3 I 1 EGBGB »Rechtsordnungen«), zu denen auch nichtstaatliche Regelwerke wie die UNIDROIT Principles of International Commercial Contracts $<$ www.unilex.info $>$ gerechnet werden (Zöller/Geimer, ZPO ${ }^{23}$ [2002] \$1051 Rz. 3; ausführlich Mankowski, Überlegungen zur sach- und interessengerechten Rechtswahl für Verträge des internationalen Wirtschaftsverkehrs: RIW 2003, 2ff. [11ff.] mit weiteren Nachweisen). Zur Privatisierung des Handelsrechts vgl. nur Hadfield, Privatizing Commercial Law: Regulation 2001, 4045; Bernstein, Private Commercial Law in the Cotton Industry, Creating Cooperation through Rules, Norms, and Institutions: Mich.L. Rev. 99 (2001) 1724ff.; kritisch Wai, Transnational Liftoff and Juridical Touchdown, The Regulatory Function of Private International Law in an Era of Globalization: Colum. J. Transnat. L. 40 (2002) $209 \mathrm{ff}$. 
sondern machte auch den Rückgriff auf ein transnationales Handelsrecht jedenfalls für den europäischen Binnenhandel weitgehend überflüssig ${ }^{54}$.

Zum anderen wird vermutet, daß grenzüberschreitende Verbraucherverträge aufgrund der Etablierung und Verbreitung des elektronischen Geschäftsverkehrs im Binnenmarkt und darüber hinaus von der Ausnahme zum Normalfall, jedenfalls zum Massenphänomen werden könnten ${ }^{55}$. Die Plausibilität dieser Annahme beruht auf der schlichten Erkenntnis, daß ein grenzüberschreitender Direktvertrieb an Verbraucher bisher an den im Hinblick auf das Volumen der einzelnen Geschäfte unverhältnismäßig hohen Transaktionskosten scheiterte, weshalb in den Außenhandel traditionell eine Reihe von professionellen Intermediären mit Bündelungsfunktion eingeschaltet sind. Versteht man unter einem Markt den idealen $\mathrm{Ort}^{56}$, an dem Angebot und Nachfrage aufeinandertreffen, so konstituiert das Internet einen virtuellen Weltmarktplatz, auf dem Information über und Kommunikation mit potentiellen Vertragspartnern nahezu in Echtzeit zu sehr geringen, entfernungsunabhängigen Kosten möglich ist. Im Kontext des elektronischen Geschäftsverkehrs kann man das Internet deshalb als "gigantische Maschine zur Reduktion von Transaktionskosten ${ }^{57}$ verstehen, die auch kleinen und mittleren Unternehmern und Verbrauchern den unvermittelten Zugang zu den Weltmärkten eröffnet. Es liegt auf der Hand, daß die durch das Internet induzierte Senkung von Transaktionskosten nicht ohne Rückwirkung auf die Außen-

54 So erheben die Principles of European Contract Law (Part I/II [1999], Part III [2002]) einerseits ausdrücklich den Anspruch, als auf Verträge anwendbares Recht von den Parteien gewählt werden zu können (Art. 1:101 Abs.2), andererseits verstehen sie sich als rechtsvergleichende Grundlegung und damit wissenschaftliche Vorarbeit für ein Europäisches Vertragsrecht, so daß ihr Status als private Rechtsordnung durch eine europäische Kodifikation obsolet würde; vgl. auch Lando, Salient Features of the Principles of European Contract Law, A Comparison with the UCC: Pace Int. L. Rev. 13 (2001) 339ff.; v. Bar/Lando/ Swann, Communication on European Contract Law, Joint Response of the Commission on European Contract Law and the Study Group on a European Civil Code: Eur.Rev.Priv.L. 2002, $182 \mathrm{ff}$.

$55 \mathrm{Vgl}$. schon den füften Zwischenbericht der Enquete-Kommission "Zukunft der Medien in Wirtschaft und Gesellschaft - Deutschlands Weg in die Informationsgesellschaft« zum Thema »Verbraucherschutz in der Informationsgesellschaft«, Deutscher Bundestag, Drucks. 13/11003; Federal Trade Commission/Department of Commerce, Alternative Dispute Resolution for Consumer Transactions in the Borderless Online Marketplace, November 2000; zuletzt wieder Kommission der Europäischen Gemeinschaften, Mitteilung vom 7.5. 2002, Verbraucherpolitische Strategie 2002-2006, KOM(2002)208 endg.

${ }^{56}$ Ideal im Sinne von nicht notwendigerweise physisch lokalisiert wie der mittelalterliche Marktplatz, aber dennoch in sachlicher, räumlicher und zeitlicher Hinsicht abgrenzbar; vgl. zu dieser im Kartellrecht üblichen Definition Schmidt, Wettbewerbspolitik und Kartellrecht ${ }^{5}$ (1999) $49 \mathrm{ff}$.

${ }_{57}$ Kenney/Curry, Beyond Transaction Costs: E-commerce and the Power of the Internet Dataspace (Berkeley 2000) (E-Conomy Project, Working Paper, 18). 
handelsstrukturen bleiben wird, auch wenn sich die übertriebenen Erwartungen der vergangenen Jahre nicht erfüllt haben ${ }^{58}$.

In diesem Zusammenhang ist es von besonderer Bedeutung, daß das Internet lediglich eine technische Infrastruktur ist, während es sich bei Märkten um soziale Institutionen handelt, deren Funktionsfähigkeit auf Effizienz und Vertrauen beruht, also auf Faktoren, die der sozialen Organisation bedürfen ${ }^{59}$. So wie der mittelalterliche Marktplatz nicht lediglich aus einer gepflasterten Fläche zwischen Kirche und Rathaus bestand, sondern von den an einem florierenden Handel interessierten Städten etwa durch Errichtung einer marktnahen Gerichtsbarkeit gefördert wurde ${ }^{60}$, so bedarf auch ein elektronischer Weltmarktplatz der Einbettung in soziale und rechtliche Institutionen, die das Vertrauen in die Fairneß der dort vorgenommenen Transaktionen stützen und zugleich die rechtlich begründeten Transaktionskosten so gering halten, daß sich die Potentiale des elektronischen Geschäftsverkehrs voll entfalten können ${ }^{61}$. Das Internet ist in diesem Sinne nicht schon selbst Weltmarktplatz, sondern lediglich ein Katalysator der Globalisierung von Märkten ${ }^{62}$.

c) Die Interessenlage: Verbraucherlandprinzip als Gebot der Gerechtigkeit?

Die Etablierung von Rechtssicherheit und Gerechtigkeit auf elektronischen Weltmärkten steht deshalb auf der Agenda der in der OECD organisierten Industriestaaten, die sich aus wirtschafts- und wettbewerbspolitischen Gründen einer Förderung des elektronischen Geschäftsverkehrs verschrieben

58 Übertrieben waren freilich vornehmlich die Erwartungen der Akteure an den internationalen Wertpapierbörsen, während die statistisch nachweisbaren Umsätze im E-Commerce kontinuierlich anstiegen; vgl. OECD, Measuring the Information Economy (2002) 59ff.; Unternehmensnachrichten zeigen, daß wichtige E-Commerce-Unternehmen gerade in der Wirtschaftskrise 2001/02 gewachsen sind: Die Umsätze von Amazon im dritten Quartal 2002 stiegen gegenüber dem Vorjahreszeitraum um 33\%, in Europa sogar um über 90\% (FTD vom 24.10.02).

59 Zum Verständnis von Märkten als Organisationen vgl. Richter, Die neue Institutionenökonomik des Marktes (1996) (Lectiones Jenensis, 5).

${ }_{60} \mathrm{Vgl}$. Berman, Recht und Revolution (1991) 586 mit Erläuterungen zur Freiburger Charta von 1120, die Kaufleuten die Gründung einer freien, d.h. nicht dem Landrecht, sondern dem Handelsrecht unterworfenen Stadt ermöglichte. Die berühmte Freiburger Gerichtslaube von 1278 bildet ein Beispiel für eine marktnahe Gerichtsbarkeit, vorgängig wurden Marktstreitigkeiten im Eingangsportal des Freiburger Münsters geschlichtet; zur alten lex mercatoria vgl. Milgrom/North/Weingast, The Role of Institutions in the Revival of Trade: The Medieval Law Merchant, Privat Jugdes, and the Champagne Fairs: Economics and Politics 2 (1990) $1 \mathrm{ff}$.

61 Calliess, Rechtssicherheit und Marktbeherrschung im elektronischen Welthandel, in: E-Commerce und Wirtschaftspolitik (oben N. 4) 189ff. mit weiteren Nachweisen.

62 Siehe oben bei N.1. 
haben $^{63}$. Deutschland und die Europäische Union haben inzwischen eine Reihe von Maßnahmen erlassen, die diesem Ziel dienen sollen. Dazu gehören die Anpassung von Formvorschriften und die Einführung gerichtsfester elektronischer Signaturen ebenso wie die Begründung von Informationspflichten und die Regelung von Haftungsfragen. Auf dem Gebiet des Verbraucherschutzes ging es vor allem darum, die Einhaltung des traditionellen Schutzniveaus auch im Online-Bereich sicherzustellen und gewisse Schutzlücken zu schließen ${ }^{64}$. Hingegen wurde das Kernproblem, das sich aus der Etablierung elektronischer Weltmärkte für das internationale Privat- und Zivilverfahrensrecht ergibt, zwar unter dem Gesichtspunkt "Herkunftsstaat- vs. Bestimmungslandprinzip « intensiv diskutiert, blieb aber für den Bereich grenzüberschreitender Verbraucherverträge bisher ungelöst ${ }^{65}$.

Die entscheidende Frage lautet, ob der traditionelle Regulierungsansatz des internationalen Verbrauchervertragsrechts, der (passiven) Verbrauchern den Zugang zu den Weltmärkten nur unter der Bedingung der zwingenden

$63 \mathrm{Vgl}$. OECD, Guidelines for Consumer Protection in the Context of Electronic Commerce, $1999<$ www.oecd.org > Federal Trade Commission, Bureau of Consumer Protection, Consumer Protection in the Global Electronic Marketplace, Looking Ahead, September 2000; Kommission der Europäischen Gemeinschaften, Mitteilung vom 28. 5. 2002, eEurope 2005: Eine Informationsgesellschaft für alle, KOM(2002)263 endg.; für Deutschland vgl. die Initiative D21 < www.initiatived21.de $>$.

${ }^{64}$ Folgende Maßnahmen der EU sind inzwischen in Deutschland umgesetzt: Die Fernabsatzrichtlinie vom 20.5. 1997 (97/7/EG, AB1. EG 144/19), die Signaturrichtlinie vom 13.12. 1999 (99/93/EG, ABl. EG 2000 L 13/12) und die E-Commerce-Richtlinie vom 8.6. 2000 (2000/31/EG, ABl. EG L 178/1). Vgl. Reich/Nordhausen, Verbraucher und Recht im elektronischen Geschäftsverkehr (eG) (2000); Pützhoven, Europäischer Verbraucherschutz im Fernabsatz (2001); Glatt, Vertragsschluss im Internet (2002); Dilger, Verbraucherschutz bei Vertragsabschlüssen im Internet (2002). Das Prinzip der Gleichbehandlung von Offline- und Online-Geschäften findet sich in den OECD Guidelines for Consumer Protection in the Context of Electronic Commerce von 1999 (General Principles I.).

${ }_{65}$ Für das öffentliche Wirtschaftsaufsichtsrecht begründet die E-Commerce-Richtlinie das Herkunftsstaatprinzip mit Auswirkungen auf das Werbe- und Vertriebsrecht (UWG, Rabattgesetz etc.), aber ohne Wirkung im Internationalen Vertragsrecht, das anläßlich der Transformation des EVÜ in eine EG-Verordnung angepaßt werden soll; vgl. die Nachweise in N. 7; für den Gerichtsstand folgt die EuGVVO in Verbrauchersachen einem erweiterten Bestimmungslandprinzip; vgl. Gillies, A Review of the New Jurisdiction Rules for Electronic Consumer Contracts within the European Union: The Journal of Information, Law and Technology (JILT) 2001 (1); die Verhandlungen zur Hague Judgements Convention oszillieren ebenfalls zwischen Herkunfsstaat- und Bestimmungslandprinzip, wobei allgemein die Bedeutung von Softlaw (Online-Dispute-Resolution) hervorgehoben wird; vgl. Haines, The Impact of the Internet on the Judgements Project, Thoughts for the Future, in: Hague Conference on Private International Law, Preliminary Document No 17 of February 2002; Reich/Gambogi Carvalho, Gerichtsstand bei internationalen Verbrauchervertragsstreitigkeiten im e-commerce, Die EG-Verordnung 44/2001 vom 22. 12. 2000 und der Haager Konventionsentwurf über die gerichtliche Zuständigkeit und die Anerkennung und Vollstreckung ausländischer Entscheidungen in Zivil- und Handelssachen: VuR 2001, 269-280. 
Geltung der Schutzvorschriften ihres Heimatrechts gewährt, für den elektronischen Geschäftsverkehr lediglich fortentwickelt werden muß, oder ob die Emergenz eines elektronischen Weltmarktplatzes der künstlichen Nationalisierung von grenzüberschreitenden Verbraucherverträgen nicht Grenzen setzt und über kurz oder lang in Richtung auf ein internationales oder transnationales Einheitsrecht drängt ${ }^{66}$. Die Interessenlage der Verbraucher ist insoweit keineswegs eindeutig. Statistische Untersuchungen der Konsumgütermärkte ergeben selbst zwischen den Mitgliedstaaten der Europäischen Union Preisdifferenzen, die sich innerhalb eines funktionierenden Binnenmarkts objektiv nicht rechtfertigen lassen und nur auf die weitgehende faktische $\mathrm{Ab}$ schottung der nationalen Verbrauchermärkte zurückgeführt werden können ${ }^{67}$. Das gilt um so mehr für den Außenhandel mit Drittstaaten, wo in Abhängigkeit von den Devisenkursen mitunter exorbitante Handelsspannen erzielt werden ${ }^{68}$.

Das Europarecht gibt den Verbrauchern zwar einerseits einen Anspruch auf ein "hohes Verbraucherschutzniveau", andererseits vermitteln die Grundfreiheiten den Verbrauchern aber auch ein »Recht auf Zugang zu den europäischen Märkten « ${ }^{69}$. Wenn und soweit aber das Verbraucherlandprinzip dem Zugang zu ausländischen Märkten hinderlich ist, weil es die faktische Zersplitterung der nationalen Verbrauchermärkte auf rechtlicher Ebene spiegelt

${ }_{66}$ Vgl. Calliess, Globale Kommunikation (oben N. 1) 74ff.; kritisch Mankowski, Cyberlaw (oben N. 49) $138 \mathrm{ff}$.

${ }^{67} \mathrm{Vgl}$. etwa Kommission der Europäischen Gemeinschaften, Verbraucherpolitische Strategie (oben N. 55) unter 2.3.3. mit weiteren Nachweisen. Deutlich wird diese Marktsegmentierung insbesondere an den Preisdifferenzen im Automobilsektor, vgl. dazu die Angaben auf der Homepage der Generaldirektion Wettbewerb: <http://europa.eu.int/comm/competition/car_sector/price_diffs $>$.

68 Von deutschen Autoherstellern ist etwa bekannt, daß diese bei hohen Dollarkursen zeitweise ihren gesamten Konzerngewinn einzig dem Vertrieb in den USA verdanken. Insgesamt liegen die hohen Preisdifferenzen häufig in den Wettbewerbsbeschränkungen im internationalen Handel begründet, die aus den vielfältigen Vertriebsbindungen der Markenhersteller resultieren, insofern diese selektive Vertriebsstrategien verfolgen. Vgl. Handbuch des Vertriebsrechts, hrsg. von Martinek/Semler (1996); zu der kartellrechtlichen Problematik vgl. Verordnung (EG) Nr. 2790/1999 vom 22.12.1999 über die Anwendung von Artikel 81 Absatz 3 des Vertrages auf Gruppen von vertikalen Vereinbarungen und aufeinander abgestimmten Verhaltensweisen, ABl. EG L 336/21; Mitteilung der Kommission, Leitlinien für vertikale Beschränkungen, ABl. EG C 291/01; Polley/Seeliger, Die neue Gruppenfreistellungsverordnung für Vertikalverträge Nr. 2790/1999, Ihre praktische Anwendung: WRP 2000, 1203ff.; Immenga/Mestmäcker(-Emmerich), Gesetz gegen Wettbewerbsbeschränkungen ${ }^{3}$, GWB (2001) Kommentierung zu $\$ 14$; sowie Verordnung (EG) Nr. 1400/2002 der Kommission vom 31.7. 2002 über die Anwendung von Artikel 81 Absatz 3 des Vertrags auf Gruppen von vertikalen Vereinbarungen und aufeinander abgestimmten Verhaltensweisen im Kraftfahrzeugsektor, ABl. EG L 203/30; zur Preisdifferenzierung bei segmentierten Märkten vgl. auch Siebert (oben N. 48) 108f., $131 \mathrm{ff}$.

69 Zum »hohen Verbraucherschutzniveau«vgl. Art. 153 I EG; zum aus den Grundfreiheiten folgenden Recht auf Zugang des Verbrauchers zum Binnenmarkt vgl. nur Reich, Bürgerrechte in der Europäischen Union (1999) 266f. ("passive Marktfreiheiten«). 
und damit zementiert, so stellt sich die Frage, ob der traditionelle Rechtsrahmen den Interessen der Verbraucher angesichts der mit dem elektronischen Geschäftsverkehr eröffneten Marktzutrittschancen überhaupt dienlich ist. Bei der Abwägung der involvierten Rechte und Interessen kann jedenfalls nicht mehr umstandslos davon ausgegangen werden, daß ein hohes Verbraucherschutzniveau ausschließlich und gerade durch die Anwendung des Heimatrechts des Verbrauchers zu verwirklichen ist ${ }^{70}$. Unter dem Gesichtspunkt der Erforderlichkeit einer mit dem Verbraucherlandprinzip verbundenen Beschränkung des Rechts auf freien Zugang des Verbrauchers zu den Weltmärkten $^{71}$ ist vielmehr zu untersuchen, ob ein hohes Verbraucherschutzniveau nicht durch ebenso geeignete, aber im Hinblick auf Marktzutrittsbarrieren mildere Mittel erreicht werden kann ${ }^{72}$.

d) Alternativen: gegenseitige Anerkennung und europäisches Einheitsrecht

Solche Alternativen zum geltenden Rechtsrahmen für grenzüberschreitende Verbraucherverträge werden gegenwärtig im Kontext der Mitteilung der Europäischen Kommission zum Europäischen Vertragsrecht diskutiert ${ }^{73}$. Die Kommission hat dabei vier Handlungsoptionen zur Diskussion gestellt: Abgesehen vom bloßen Nichtstun im Vertrauen auf eine Selbstregulierung des Marktes (Option 1) sowie der weiteren Förderung von Restatements nach dem Vorbild der Lando Principles (Option 2) sind vorliegend vor allem die folgenden Alternativen von Interesse: Zum einen bietet sich eine Konsolidierung des existierenden Richtlinienrechts (acquis communautaire) mit

70 Dies gilt um so mehr, als schon die das Verbraucherlandprinzip tragende Grundannahme, das nationale Verbraucherschutzniveau sei dem Verbraucher "vertraut", wenig realistisch ist. Nach der Schuldrechtsreform muß gegenwärtig davon ausgegangen werden, daß schon in weiten Teilen der deutschen Richter- und Anwaltschaft das deutsche Verbrauchervertragsrecht wenn nicht unbekannt, so doch jedenfalls unvertraut ist. Für Verbraucher als juristische Laien kann allenfalls von einem generalisierten Vertrauen darauf ausgegangen werden, daß ihre Interessen bei Anwendung deutschen Rechts angemessen berücksichtigt werden, wobei dieses Vertrauen in der Praxis im internationalen Vergleich als wenig gerechtfertigt erscheint; vgl. Comparative Report on Consumer Policy Regimes (2003), im Internet unter <www.dti.gov.uk/ccp/publications.htm>.

71 Virulent ist dieses Problem vor allem für Verbraucher aus kleineren Mitgliedstaaten. Welcher Unternehmer würde etwa ernsthaft erwägen, eine eigenständige Vertriebsstrategie mit angepaßten Werbemaßnahmen, eigenständigen AGB und Widerrufsbelehrungen für eine Handvoll potentieller Kunden in Luxemburg oder Litauen zu etablieren?

72 Zum Verhältnismäßigkeitstest der EuGH-Grundfreiheiten-Rechtsprechung Reich (oben N.69) $264 \mathrm{ff.}$

73 KOM(2001)398 endg. vom 11.7. 2001, welche einschließlich aller Stellungnahmen und Nachfolgedokumente, insbesondere dem Aktionsplan KOM(2003)68 endg. vom 12. 2. 2003, über die Homepage der GD Verbraucher erhältlich ist: < http://europa.eu.int/ comm/consumers/index_de.htm>. 
dem Ziel der Schaffung eines kohärenten Rechtsrahmens für grenzüberschreitende Verbraucherverträge an, der die Privatrechtsordnungen der Mitgliedstaaten so weitgehend harmonisiert, daß für die verbleibenden Unterschiede das Prinzip der gegenseitigen Anerkennung im Sinne der Cassis-Philosophie eingreifen kann (Option 3). Dieses Vorgehen hätte den Vorteil, daß unter Aufgabe des Verbraucherlandprinzips des Art. 5 EVÜ Unternehmen ein europaweites Vertriebskonzept einheitlich nach dem Privatrecht ihres Herkunftsmitgliedsstaates organisieren könnten, was die rechtlichen Transaktionskosten erheblich reduzieren würde.

Zum anderen wird die Schaffung einer Europäischen Kodifikation erwogen, wobei sich im Hinblick auf deren Anwendungsbereich verschiedene Möglichkeiten ergeben: Ein Europäisches Zivilgesetzbuch könnte nur für grenzüberschreitende Verträge oder für alle Verträge Geltung beanspruchen, es könnte von den Vertragsparteien im Wege der Rechtswahl anwählbar oder abwählbar bzw. nur abwählbar sein, soweit nicht zwingende Vorschriften des Verbraucherschutzes betroffen sind (Option 4). Unabhängig von den vielfältigen Vor- und Nachteilen eines Europäischen Zivilgesetzbuches ${ }^{74}$ läßt sich an dieser Stelle feststellen, daß sich ein solches Kodifikationsvorhaben als um so problematischer darstellt, je umfassender und zwingender dessen Anwendungsbereich ist. Denn die ohnehin im europäischen Verbrauchervertragsrecht angelegte Tendenz zu einer weitgehenden Ersetzung der Vertragsfreiheit durch halbzwingende Schutzvorschriften birgt die Gefahr in sich, daß eine Europäische Kodifikation vermeintlich einzig richtige Lösungen der Vertragsgerechtigkeit auf Kosten von Flexibilität und Innovationsoffenheit des Privatrechts festschreibt ${ }^{75}$ und damit gerade die mit der Internetkommunikation verbundenen Potentiale für ganz neuartige Verbraucherschutzlösungen behindert.

74 Diese sind nicht Gegenstand dieser Untersuchung; vgl. aber aus der Vielzahl der aktuellen Stellungnahmen die Beiträge in: An Academic Green Paper on European Contract Law, hrsg. von Grundmann/Stuyck (2002); Staudenmayer, The Commission Communication on European Contract Law and the Future Prospects: Int. Comp. L. Q. 51 (2002) 673688; Schlechtriem, Wandlungen des Schuldrechts in Europa-wozu und wohin: ZEuP 2002, 213ff.; Kötz, Alte und neue Aufgaben der Rechtsvergleichung: JZ 2002, 257ff.; Schwintowski, Auf dem Weg zu einem Europäischen Zivilgesetzbuch: ebd. 205ff.; Sonnenberger 489ff.; Grundmann 329ff. (beide oben N. 49). - Zum Aktionsplan KOM(2003)68 sowie zur Reform des EVÜ KOM(2002)654 endg. vgl. Calliess, Coherence and Consistency in European Consumer Contract Law, A Progress Report: German L.J. 4 (2003) No. 4, im Internet unter $<$ www.germanlawjournal.com $>$.

75 Dies scheint auch die Befürchtung zu sein, die der ablehnenden Haltung vieler Stellungnahmen aus der Wirtschaft gegenüber einem Europäischen Zivilgesetzbuch zugrunde liegt. Vgl. dazu Ott/Schäfer (oben N.40); dagegen aber für einen optionalen Code zu Recht der Kommentar von Eidenmüller, Obligatorisches versus optionales europäisches Vertragsgesetzbuch, in: Vereinheitlichung und Diversität des Zivilrechts in transnationalen Wirtschaftsräumen (oben N. 7) $237 \mathrm{ff}$. 
e) Leerstellen: Grenzen der europäischen Rechtsvereinheitlichung

Ungeachtet dessen kann eine Vereinheitlichung des materiellen Verbrauchervertragsrechts auf europäischer Ebene zwei Probleme nicht lösen: Aufgrund der Ubiquität des Internets besteht jedenfalls im Falle der digitalisierbaren Güter und Dienstleistungen aus Verbrauchersicht kein relevanter Unterschied zwischen Europa und dem Rest der Welt: die faktischen Transaktionskosten sind identisch, das Internet konstituiert insoweit ein global level playing field. Ein europäisches Einheitsrecht würde aber im Verhältnis zu Drittstaaten weiterhin der kollisionsrechtlichen Problematik unterliegen. Aus Sicht der Anbieter aus Drittstaaten bedeutete dies dennoch einen Fortschritt, insofern eine einheitliche europäische Vertriebsstrategie ermöglicht würde, deren Kosten bei einem Markt von demnächst knapp 500 Millionen Verbrauchern $^{76}$ als marginal, jedenfalls als auch für kleinere Unternehmen tragbar erscheinen.

Wesentlich schwerer wiegt hingegen ein prozessuales Problem: ein materielles Einheitsrecht trägt wenig dazu bei, den Zugang der Verbraucher zum Recht (access to justice) zu verbessern. Bei geringen Streitwerten lohnt sich die Inanspruchnahme staatlichen Rechtsschutzes schon auf nationaler Ebene nicht ${ }^{77}$. Trotz gewisser mit der EuGVVO ${ }^{78}$ verbundener Vereinfachungen bei der gegenseitigen Anerkennung und Vollstreckung von Urteilen gilt dies auch im grenzüberschreitenden europäischen Rechtsverkehr, wo nach einer Untersuchung der European Consumer Law Group bei einem Streitwert von $2000 €$ Kosten von durchschnittlich knapp $2500 €$ entstehen $^{79}$. Immerhin

76 Von den derzeit 13 Kandidaten werden in der jetzt anstehenden Erweiterungsrunde mit Ausnahme von Bulgarien, Rumänien und der Türkei alle Staaten aufgenommen, so daß die EU ca. 478 Mio. Bürger haben wird. Insoweit sich der EFTA-Staat Norwegen und weitere Staaten wie die Schweiz, die bereits über das an das EuGVÜ angelehnte LugÜ an der europäischen Kooperation in Zivil- und Handelssachen teilhaben, der Sogwirkung eines Europäischen Zivilgesetzbuchs nicht entziehen könnten, würde dieser Raum nochmals erweitert.

77 Vgl. nur Scherpe, Außergerichtliche Streitbeilegung in Verbrauchersachen (2002) 8ff. mit ausführlichen Nachweisen zur Access-to-Justice-Forschung.

78 Verordnung (EG) Nr. 44/2001 des Rates vom 22.12.2000 über die gerichtliche Zuständigkeit und die Anerkennung und Vollstreckung von Entscheidungen in Zivil- und Handelssachen, ABl. EG 2001 L 12/1; vgl. dazu Junker, Vom Brüsseler Übereinkommen zur Brüsseler Verordnung, Wandlungen des Internationalen Zivilprozeßrechts: RIW 2002, $569 \mathrm{ff}$.

79 Siehe hierzu insbesondere das Grünbuch der Kommission vom 9.2.2000 »Prozeßkostenhilfe in Zivilsachen: Probleme der Parteien bei grenzüberschreitenden Streitsachen", KOM(2000)51 endg.; vgl. European Consumer Law Group, Jurisdiction and applicable law in cross-border consumer complaints - Socio-legal remarks on an ongoing dilemma concerning effective legal protection for consumer-citizens in the European Union, ECLG/157/ 98 - 29/04/98; vgl. auch die Studie von Feldtmann/v. Freyhold/Vial, The Cost of Legal Obstacles to the Disadvantage of Consumers in the Single Market, A Report for the European Commission (1998). 
würde ein materielles Einheitsrecht nicht nur die gegenseitige Anerkennung von Urteilen erleichtern, sondern auch zu mehr Rechtssicherheit im Sinne der Vorhersehbarkeit gerichtlicher Entscheidungen und damit zu einer Beschleunigung der Verfahren führen. Die gegenwärtigen Inkonsistenzen im europäischen Verbrauchervertragsrecht provozieren demgegenüber immer wieder Vorlagen an den Europäischen Gerichtshof, wodurch die endgültige Klärung eines Streits oft Jahre in Anspruch nimmt, was in der Literatur bereits zu einem Vergleich des europäischen Gerichtssystems mit der von Kleists Michael Kohlhaas erfahrenen Justizverweigerung geführt hat (justice delayed is justice denied) $)^{80}$.

\section{Phänomene eines transnationalen Verbrauchervertragsrechts}

Aus der Debatte um die lex mercatoria ist bekannt, daß sich bei hinreichender Ineffizienz der staatlichen Rechtssysteme quasi automatisch ein Wettbewerb privater Rechtsregimes etabliert, die das vom Staat eröffnete normative Vakuum ausfüllen, indem sie die transnationale Nachfrage nach Rechtssicherheit und Gerechtigkeit durch private Dienstleistungsangebote $\mathrm{zu}$ befriedigen suchen (private ordering) ${ }^{81}$.

\section{a) Selbstregulierung im internationalen Handel}

Im internationalen Handel sind dies zunächst Selbstschutzmechanismen, die die Wahrscheinlichkeit von vertragsbrüchigem Verhalten minimieren. Dazu gehören Informationsbroker, die den Markt für Reputation transparent gestalten (Wirtschaftsauskunfteien, Rating-Agenturen), ebenso wie die Ein-

${ }^{80}$ Joerges, The Bright and the Dark Side of the Consumer's Access to Justice in the EU: Global Jurist Topics 1 (2001) No. 2, [ohne Paginierung, 1. Artikel im Heft]; zur Diskussion um die Notwendigkeit einer europäischen Justizreform vgl. auch die Beiträge zum Schwerpunktthema »Europäische Gerichtsbarkeit, Erfahrungen und Reformdiskussion im Lichte des europäischen Privatrechts«: RabelsZ 66 (2002) 201-631, insbes. Reich, Die Vorlagepflicht auf teilharmonisierten Rechtsgebieten am Beispiel der Richtlinien zum Verbraucherschutz: ebd. $531 \mathrm{ff}$, der ausführt, daß das Vorlageverfahren zum EuGH häufig als "rechtspolitische Reparaturwerkstatt« (a.a.O. 551) diene, wie u.a. am Heininger-Fall erkennbar sei.

${ }^{81} \mathrm{Vgl}$. den Forschungsansatz der New Institutional Economics of International Trade (NIEIT): Schmidtchen/Schmidt-Trenz, The Division of Labour is limited by the extent of the Law: Constitutional Political Economy 1 (1990) 1ff.; Streit/Mangels, Privatautonomes Recht und grenzüberschreitende Transaktionen: ORDO 47 (1996) 73ff.; Schmidtchen (oben N. 49) mit weiteren Nachweisen; ähnlich - wenngleich eher als radikale Kritik am (staatlichen) Recht formuliert - auch der Ansatz bei Posner (oben N. 42); zum dort entwikkelten Konzept der Normunternehmer vgl. auch Engert, Wettbewerb sozialer Normen und Sanktionierung durch das Recht: Jb. Junger Zivilrechtswiss. 2002 (2003) 31ff.; vgl. auch Hadfield und Bernstein (beide oben N. 53). 
beziehung vertrauenswürdiger Dritter in die Vertragsabwicklung (Akkreditiv), die Errichtung von langfristigen Kooperationsnetzwerken (relationale Verträge) oder die Internalisierung von transnationalen Marktbeziehungen in hierarchische Organisationen (multinationale Unternehmen). Auch Versicherungen können zur Reduktion der Risiken des internationalen Handels beitragen, wobei nicht jedes Vertragsbruchrisiko auf dem Markt versicherbar ist. Beispiele sind etwa die Übernahme von Risiken durch Dritte im Wege der Forfaitierung, des Factoring sowie der Außenhandelskreditversicherung (Fremdversicherung) oder die strategische, auch über Unternehmenskäufe realisierte Umsatzsteigerung bis zur Erreichung der kritischen Größe eines global player (Selbstversicherung) ${ }^{82}$. Schließlich sind die Einrichtung alternativer Streitschlichtungsinstanzen in der internationalen Handelsschiedsgerichtsbarkeit (International Court of Arbitration der International Chamber of Commerce [ICC]) sowie materiellrechtliche Angleichungsinstrumente wie standardisierte Vertragsklauseln (Incoterms und Modellverträge der ICC) und Privatkodifikationen allgemeiner Vertragsrechtsprinzipien (UNIDROIT oder Lando Principles) zu erwähnen, die die lex mercatoria im eigentlichen Sinne konstituieren ${ }^{83}$.

b) Selbstregulierung auf nationalen und europäischen

Verbrauchermärkten

Auf den nationalen Verbrauchermärkten sind vergleichbare Selbstschutzmechanismen hingegen nicht etabliert, was auf die relativ zur Effizienz staatlichen Rechtsschutzes sowie zum Transaktionsvolumen prohibitiven Opportunitätskosten der Inanspruchnahme solcher privater Dienstleistungen zurückgeführt werden $\mathrm{kann}^{84}$. Zwar existiert eine Vielzahl von insbesondere branchenspezifischen Angeboten wie etwa die Schlichtungsstellen des Kammerwesens oder die Ombudsleute der Finanzdienstleister. Deren Attraktivität scheint aus Verbrauchersicht freilich so gering zu sein, daß der Zugang zum staatlichen Recht aus Gründen der Justizentlastung jüngst sogar künstlich er-

82 Eine Einführung in diese Mechanismen des internationalen Handelsrechts bei Altmann, Außenhandel für Unternehmen ${ }^{2}$ (2001) Kap. D-H; Jahrmann (oben N. 48) Kap. C, E, H, J; umfassend Handbuch für Kaufrecht, Rechtsdurchsetzung und Zahlungssicherung im Außenhandel, hrsg. von Häberle (2002); aus juristischer Sicht Graf von Bernstorff, Rechtsprobleme im Auslandsgeschäft ${ }^{4}(2000)$.

${ }^{83} \mathrm{Vgl}$. die Nachweise in N.27 ff., 49 f. und 82.

${ }^{84} \mathrm{Zu}$ den Opportunitätskosten gehören insbesondere die Transaktionskosten, der Begriff weist aber auf die Einbeziehung der Kosten (unterlassener) Alternativhandlungen hin (zu den Kosten der Freizeit gehört der Verdienstausfall unterlassener Arbeit und umgekehrt). Vorliegend ist damit gemeint, daß der rationale Verbraucher angesichts einer Vertragsstörung mit geringem Streitwert bei der Entscheidung über die Inanspruchnahme von ADR-Mechanismen die Kosten der Handlungsalternativen Nichtstun/Abwanderung und Klage vor staatlichen Gerichten abwägen muß. 
schwert worden ist: $\$ 15$ a EGZPO ermächtigt die Länder, den Zugang zu den Gerichten bei geringen Streitwerten von der vorherigen erfolglosen Inanspruchnahme eines anerkannten Streitschlichtungsverfahrens abhängig zu machen $^{85}$.

Auch die Versuche der Europäischen Union, für grenzüberschreitende Verbraucherverträge ein Netzwerk von außergerichtlichen Streitbeilegungsstellen zu etablieren (EEJ-Net und FIN-Net), sind bisher nicht von durchschlagendem Erfolg gekrönt ${ }^{86}$. Trotz der Einrichtung von Informationszentren weiß praktisch niemand von diesen Möglichkeiten, und die Einleitung des im Vergleich zum Gerichtsverfahren sogar umständlicheren Verfahrens mit ungewissem Ausgang erscheint wenig attraktiv ${ }^{87}$. Im traditionellen Umfeld verzichtet jedenfalls der rationale Verbraucher im Falle von Enttäuschungen bei kleinen Transakationsvolumen regelmäßig auf eine streitige Durchsetzung seiner Rechte zu Gunsten der zukünftigen Abwanderung zu anderen Anbietern, während er bei höheren Streitwerten auf bekannte Markenanbieter, die einen guten Ruf zu verlieren haben, setzen $\mathrm{kann}^{88}$. Im Zweifelsfalle scheint aber das staatliche Gerichtssystem eine hinreichend effektive Option zu sein, wobei das Risiko der Rechtsdurchsetzung mit Hilfe einer Rechtsschutzversicherung oder des Prozeßkostenhilfeverfahrens minimiert werden $\mathrm{kann}^{89}$.

85 Vgl. Scherpe (oben N. 77) mit weiteren Nachweisen; Friedrich, Aktuelle Entscheidungen zu \$15a EGZPO: NJW 2002, 3223ff.; ders., Die Anerkennung der alternativen Streitbeilegung durch die neuere Gesetzgebung im Zivil- und Zivilprozeßrecht: JR $2002397 \mathrm{ff}$.

86 Grünbuch der Kommission über alternative Verfahren zur Streitbeilegung im Zivilund Handelsrecht vom 19. 4. 2002, KOM(2002)196 endg. mit weiteren Nachweisen. Zum European Extra Judicial Network siehe auch $<$ www.eejnet.org $>$; zum Pendant für Finanzdienstleistungen FIN-NET siehe die Angaben unter <http://europa.eu.int/comm/ internal_market/en/finances/consumer/adr.htm>.

${ }^{87}$ Im Gegensatz zum Verbrauchergerichtsstan d der EuGVVO beruht das EEJ-Net auf dem Prinzip der Zuständigkeit der Schlichtungsstellen im Heimatstaat des Unternehmers, die nationalen Anlaufstellen verweisen den Verbraucher also lediglich an diese ausländischen Stellen und helfen bei Sprachproblemen. Freilich ist das Projekt erst in der Anlaufphase, so daß ein endgültiges Urteil über den Erfolg derzeit nicht ansteht.

${ }_{88}$ Markenanbieter mit einem kulanten Customer Relationship Management gibt es zwar auch bei sehr billigen Produkten. Die Reklamation einer mangelhaft befüllten Tüte Cornflakes lohnt sich aber nicht, weil schon der Anruf oder Brief (bei Einbeziehung der Opportunitätskosten) teurer als das Produkt ist.

89 Weshalb die Europäische Kommission auch auf diesem Gebiet tätig werden will: Grünbuch der Kommission vom 9.2.2000 »Prozeßkostenhilfe in Zivilsachen: Probleme der Parteien bei grenzüberschreitenden Streitsachen«, KOM(2000)51 endg.; vgl. auch Art. 47 III der Charta der Grundrechte der EU; und den Vorschlag der Kommission für eine Richtlinie des Rates zur Verbesserung des Zugangs zum Recht bei Streitsachen mit grenzübergreifendem Bezug durch die Festlegung gemeinsamer Mindestvorschriften für die Prozeßkostenhilfe und für andere mit Zivilverfahren verbundene finanzielle Aspekte vom 18.1. 2002 (KOM[2002]13 endg.). 
c) Selbstregulierung auf dem elektronischen Weltmarktplatz

Als Akteur auf den elektronischen Weltmärkten sieht sich der Verbraucher hingegen ähnlichen Rechtsanwendungs- und Rechtsdurchsetzungsrisiken ausgesetzt wie traditionell nur die internationale Kaufmannschaft ${ }^{90}$. Es erstaunt daher nicht, wenn sich im elektronischen Geschäftsverkehr gegenwärtig eine Vielzahl von Anbietern zu etablieren suchen, die private Ordnungsdienstleistungen offerieren ${ }^{91}$ : Als Informationsbroker dienen etwa Verbraucherportale, die über reflexive Bewertungssysteme einen Erfahrungsaustausch über Produkte und Anbieter vermitteln ${ }^{92}$; Trustmarkprovider vergeben Gütesiegel an geprüfte Unternehmen, die in einem Code of Conduct niedergelegte Anforderungen an Sicherheit, Zuverlässigkeit, Verbraucherund Datenschutz befolgen ${ }^{93}$; Online Dispute Resolution (ODR) Service Provider bieten alternative Streitschlichtungsverfahren von der Mediation bis zur Schiedsgerichtsbarkeit an ${ }^{94}$; und insbesondere Payment Service Provider bieten Charge-Back-Verfahren, dem Akkreditiv vergleichbare Escrow-Services $^{95}$, Gewährleistungsversicherungen ${ }^{96}$ oder Geld-zurück-Garantien im Fal-

90 Vgl. nur Rothchild, Protecting the Digital Consumer, The Limits of Cyberspace Utopianism: Indiana L. J. 74 (1999) 893-998; Federal Trade Commission, Bureau of Consumer Protection, Consumer Protection in the Global Electronic Marketplace, Looking Ahead, September $2000<$ www.ftc.gov $>$.

$91 \mathrm{Vgl}$. dazu insgesamt Perritt, Dispute resolution in cyberspace, Demand for new forms of ADR: Ohio State Journal on Dispute Resolution 15 (2000) 675ff.; Katsh/Rifkin, Online Dispute Resolution, Resolving Conflicts in Cyberspace (2001); Hörnle, Online Dispute Resolution in Business to Consumer E-commerce Transactions: JILT 2002, Issue 2 [ohne Paginierung]; Davis, Building the Seamless Dispute Resolution Web, A Status Report on The American Bar Association Task Force on E-Commerce and Alternative Dispute Resolution: Tex. Wesleyan L. Rev. 8 (2002) 529ff.; Anderson/Cole, The UDRP, A Model for Dispute Resolution in E-Commerce?: J. Small \& Emerging Bus. L. 6 (2002) 235ff.; de Bruin, Consumer Trust in Electronic Commerce, Time for Best Practice (2002).

$92 \mathrm{Vgl}$. <www.epinions.com $>$ und $<$ www.doyoo.de $>$ : die Objektivität wird durch Reflexivität der Bewertungen erreicht, die Leser bewerten also die Nützlichkeit primärer Bewertungen, die besten Bewerter werden ausgezeichnet.

93 Z.B. <www.trustedshops.de> oder <www.bbbonline.org > ; vgl. den Überblick in Annex I zu Global Business Dialogue on Electronic Commerce, GBDe, Trustmark, September 26, $2000<$ www.gbde.org $>$.

94 Z.B. <www.squaretrade.com oder www.adr.org >; vgl. International Chamber of Commerce (ICC), Out-of-court settlement of disputes concerning e-commerce consumer transactions. An inventory of current approaches $<$ www.iccwbo.org/home/ADR/inventoryhome.asp $>$, wo 22 ODR-Anbieter verglichen werden.

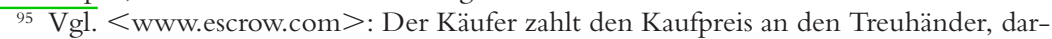
aufhin versendet der Verkäufer die Ware, der Treuhänder zahlt den Kaufpreis aus, wenn die Ware beim Käufer eingetroffen ist. Bei Streitigkeiten im Falle eines vereinbarten Rücktrittsrechts oder (vermeintlicher) Schlechtlieferung zahlt der Treuhänder erst auf gemeinsame Weisung der Parteien oder eines involvierten Streitschlichters.

${ }_{96} \mathrm{Vgl}$. < http://smart.newcorp.com/ebay/jsp/EBAY-AboutNEW.jsp>: Für neue oder 
le von Leistungs- oder Rückabwicklungsstörungen $\mathrm{an}^{97}$. Auch werden neuerdings globale Internetrechtsschutzversicherungen für Verbraucher beworben, wobei sich der Versicherer vorbehält, den Schaden selbst auszugleichen, anstatt einen internationalen Prozeß zu finanzieren ${ }^{98}$.

Die Konkurrenzfähigkeit solcher Dienstleistungen für Verbraucherverträge mit geringen Umsätzen gründet dabei einerseits darauf, daß sich die Anbieter die radikale Senkung der Informations- und Kommunikationskosten im Internet zunutze machen können ${ }^{99}$. Private Ordnungs- und Streitschlichtungsdienstleistungen für den E-Commerce sind selbst Teil des elektronischen Geschäftsverkehrs. Andererseits werden internettypisch innovative Geschäftsmodelle verfolgt, die auf eine Finanzierung durch Werbung oder auf eine Beteiligung an den bei Dritten generierten Umsätzen zielen. Das von privaten Ordnungsdienstleistern erzeugte Verbrauchervertrauen wird gleichsam an die primären Anbieter von Waren und Dienstleistungen verkauft, die diese Kosten in Erwartung von Umsatzsteigerungen auf ihre Kunden umlegen können. Zum Teil sind auch not-for-profit-Anbieter involviert und eine Reihe von Anbietern werden in der Start-up-Phase staatlich gefördert, weil die von ihnen erbrachten Ordnungsleistungen als gemeinnützig angesehen werden ${ }^{100}$.

d) Die Rolle virtueller Marktplätze

Eine wichtige Funktion erfüllen in diesem Zusammenhang die Betreiber von virtuellen Marktplätzen. Denn mehr noch als die mittelalterlichen Hafen-, Messe- und Marktstädte stehen Betreiber von elektronischen Markt-

gebrauchte Elektrikwaren wird eine nach Wert der Ware im Preis gestaffelte, unabhängige Gewährleistungsversicherung angeboten, deren Kosten je nach Vereinbarung vom Käufer oder vom Verkäufer getragen werden.

${ }_{97} \mathrm{Vgl}$. etwa das Angebot Amazon.com ("A-to-z Guarantee«), wo eine subsidiäre Ausfallhaftung übernommen wird, soweit die Bezahlung von Transaktionen auf dem Amazon Marketplace über Amazon Payments abgewickelt wird. Eine Geld-zurück-Garantie bieten der von eBay übernommene E-Payment Service Provider <www.paypal.com $>$ sowie der Trustmark Provider $<$ www.trustedshops.de $>$.

98 Nahezu alle großen Rechtsschutzversicherer bieten inzwischen einen "weltweiten Internet-Rechtsschutz .

${ }_{99}$ Der entscheidende Schritt vom traditionellen ADR zum ODR besteht in der Senkung der Transaktionskosten in Form von Such- und Informationskosten. Während sich im Offline-Bereich die Inanspruchnahme von Auskunfteien oder Streitschlichtung nur bei sehr hohen Volumen lohnt, sind diese im Online-Bereich nur einen Mouse-Click entfernt. Gleichzeitig steigen die Kosten des Zugangs zu den staatlichen Gerichten.

100 Zum europäischen Forschungsverbund EClip siehe $<$ www.eclip.org $>$. Der von den Initiatoren geplante ODR-Provider ECODIR (Electronic Consumer Dispute Resolution) hat kürzlich seine Arbeit aufgenommen, $<$ www.ecodir.org $>$. Ein Überblick über von der EU geförderte Forschungsaktivitäten findet sich unter <http://econfidence.jrc.it>. 
plätzen in einem internationalen Wettbewerb um Anbieter und Nachfrager. Für die Attraktion von Umsätzen kommt es dabei vergleichbar dem modernen Wettbewerb der Finanzplätze nicht nur auf die Bereitstellung einer effizienten technischen Infrastruktur an, sondern auch auf die Einrichtung eines "sicheren Hafens", der das Vertrauen der potentiellen Kunden in die Fairneß der auf dem Markt vorgenommen Transaktionen stärkt. So wie die internationalen Wertpapierbörsen etwa Zusatzdienstleistungen bei der Abwicklung der Geschäfte übernehmen (Clearing) oder über Börsenregelwerke für bestimmte Segmente ein über die gesetzlichen Mindestanforderungen hinausgehendes $\mathrm{Maß}$ an Transparenz und Anlegerschutz zu verwirklichen suchen ${ }^{101}$, so sind auch Betreiber von virtuellen Marktplätzen bemüht, eine das Verbrauchervertrauen fördernde Marktordnung zu etablieren. Beispielhaft sei hier nur der Marktplatz für Online-Versteigerungen E-Bay erwähnt, der über detaillierte Regelwerke verfügt (policies) und ein ganzes Bündel von vertrauensbildenden Zusatzdienstleistungen wie etwa die Authentifizierung der Marktteilnehmer, ein Rating-/Tracking-System zur Information über die vergangene Performance der Käufer und Verkäufer oder die Zahlungsabwicklung mit subsidiärer Ausfallversicherung bei Nicht- oder Schlechterfüllung selbst anbietet und weitere Dienstleistungen wie Escrow oder Dispute Resolution Services von Drittanbietern in den Markt integriert ${ }^{102}$.

e) Online Dispute Resolution: zwischen Schiedsgerichtsbarkeit und Mediation

Angesichts der beschriebenen Phänomene der Selbstregulierung drängen sich gewisse Parallelen zur Entwicklung der lex mercatoria geradezu auf. In der Debatte um Rechtsfragen des Internets ist denn auch sehr frühzeitig postuliert worden, daß sich in der deterritorialisierten Sphäre des Cyberspace ein autonomes cyberlaw, eine transnationale lex informatica entwickeln wer$\mathrm{de}^{103}$. Von einer vollständigen Privatisierung von Recht kann freilich nur ge-

101 Zum Wettbewerb der Börsenplätze im Gesellschaftsrecht vgl. Adolff, Europäisches Gesellschaftsrecht: Jb. Junger Zivilrechtswiss. 2002 (2003) 61ff.; zur Befugnis der Börsen zur Aufstellung solcher zusätzlichen abwicklungsbezogenen oder publikumsschützenden Regeln in der Börsenordnung siehe $\$ 13$ IV, \S 42, 50 III Börsengesetz vom 21.6.2002 (BGB1. I 2010).

${ }_{102}$ Vgl. den Überblick in der Kategorie Safe Harbour unter < http://pages.ebay.com/ services/index.html $>$ und insbesondere für grenzüberschreitende Verträge <http:// pages.ebay.com/internationaltrading/index.html>.

${ }^{103}$ In Anlehnung an Nozicks Konzept vom Minimalstaat (Nozick, Anarchy, State, and Utopia [1974]) Post, Anarchy, State, and the Internet, An Essay on Law-Making in Cyberspace: J. Online L. 1995, [ohne Paginierung, Artikel 3]; Johnson/Post, Law and Borders, The Rise of Law in Cyberspace: Stanford L. Rev. 48 (1996) 1367ff.; Mefford, Lex Informatica, Foundations of Law on the Internet: Indiana J. Global Leg. Stud. 5 (1998) No. 1, S. $211 \mathrm{ff}$. 
sprochen werden, wenn über die materiellrechtliche Seite der privaten Kodifikation von transnationalen Rechtsgrundsätzen und den prozessualen Aspekt der Anwendung und Interpretation solcher Regeln in alternativen Streitschlichtungsmechanismen hinaus auch die vollstreckungsrechtliche Frage nach dem Zwangsmoment eines transnationalen Rechts geklärt ist.

Für die lex mercatoria kann diesbezüglich auf die über das UNÜ gesicherte gegenseitige Anerkennung und Vollstreckung verwiesen werden ${ }^{104}$. Der Anwendungsbereich des UNÜ erstreckt sich zwar, soweit die Vertragsstaaten nicht von dem Vorbehalt für Handelssachen Gebrauch gemacht haben, auch auf die Verbraucherschiedsgerichtsbarkeit ${ }^{105}$. In Europa steht man dieser jedoch grundsätzlich kritisch gegenüber. So müssen gem. \$1031 V ZPO Schiedsvereinbarungen, an denen ein Verbraucher beteiligt ist, in einer von den Parteien eigenhändig unterzeichneten Urkunde enthalten sein, die keine anderen Vereinbarungen enthält, wobei die elektronische Form nach $\$ 126$ a BGB genügt. Mangels Verbreitung der elektronischen Signatur sind Schiedsklauseln im B2C-E-Commerce allerdings praktisch ausgeschlossen, soweit der Ort des Schiedsverfahrens in Deutschland liegt ( $\$ 1025$ I und II ZPO), während im Anerkennungsverfahren nach $\$ 1061 \mathrm{ZPO}$ und wohl auch im Einredeverfahren nach $\$ 1032$ ZPO das Formstatut des Art. II 2 UNÜ, das keine spezielle Verbraucherschutzklausel enthält, vorgeht ${ }^{106}$. Die Rechtsprechung hat in AGB enthaltene Schiedsklauseln auch in Verbindung mit Rechtswahlklauseln im Hinblick auf Verbraucherverträge regelmäßig für unwirksam erklärt ${ }^{107}$. Auch die Klauselrichtlinie (93/13/EWG) enthält in Nr.1 q) des Anhangs zu Art. 3 eine - recht kryptische - Vorschrift, die Schiedsklauseln in Verbraucherverträgen im Hinblick auf eine damit verbundene Beschränkung oder Erschwerung des Zugangs zum Recht begrenzen will. ${ }^{108}$

Demgegenüber ist die Verbraucherschiedsgerichtsbarkeit in den USA grundsätzlich anerkannt; Schiedsklauseln sind sogar dann wirksam, wenn diese in AGB enthalten sind, die dem Kunden erst bei Lieferung bekanntgegeben werden (shrink-wrap-agreements), gleiches gilt auch für AGB-Schieds-

104 Vgl. die Nachweise oben N. 51 und 53.

105 Deutschland hat keinen Gebrauch von dem Vorbehalt gemacht. Vgl. die Angaben zum Status der Konvention unter $<$ www.uncitral.org/en-index.htm $>$.

106 Vgl. dazu Zöller(-Geimer) (oben N. 53) \$1031 Rz. 1ff., 4, 30 mit weiteren Nachweisen.

107 Vgl. kritisch Schlosser, Sonderanknüpfungen von zwingendem Verbraucherschutzrecht und europäisches Prozeßrecht, in: FS Steindorff (1990) 1379ff.; Aden, Rechtswahl und Schiedsklausel im Verbraucherschutz: RIW 1997, 723 ff. jeweils mit Nachweisen zur Rechtsprechung betreffend Börsentermingeschäfte. Ausführlich zur Einbeziehungs- und Inhaltskontrolle von Schiedsklauseln Wagner, Prozeßverträge (1998) 130ff., 594ff.

108 Vgl. Zöller(-Geimer) (oben N. 53) \$1030 Rz. 28; Wagner (vorige Note) 596; Palandt (-Heinrichs), BGB ${ }^{62}$ (2003) \$310 Rz. 46. 
klauseln im B2C-E-Commerce (click-wrap-agreements) ${ }^{109}$. Besondere, dem $\$ 1031 \mathrm{~V}$ ZPO vergleichbare Formanforderungen oder Informationspflichten bestehen nicht, was in letzter Zeit zunehmend zu Kritik geführt hat ${ }^{110}$. Die Gerichte halten AGB-Schiedsklauseln unter dem Gesichtspunkt der substantive unconscionability allerdings dann für unwirksam, wenn diese dem Verbraucher die Geltendmachung seiner Rechte faktisch unmöglich machen. So wurde im Fall Brower v. Gateway Inc einer Schiedsklausel die Anerkennung verweigert, die als Schiedsinstitution den ICC Court of International Arbitration benannte, weil nach dessen Regeln eine advance fee in Höhe von US\$ $4000 \mathrm{zu}$ zahlen war ${ }^{111}$.

Für die faktische Wirksamkeit verbraucherschützender Zivilregimes ist es allerdings nicht unbedingt nötig, diese entsprechend den staatlichen Anforderungen an die Anerkennung der Schiedsgerichtsbarkeit (etwa Art. II UNÜ) auszugestalten. Ausreichend kann bereits der "sanfte Zwang« innerhalb von Vertragsregimes sowie die alternative "Vollstreckung« durch den Ausschluß von wesentlichen Dienstleistungen sein. So ist etwa die UDRP der ICANN nicht als "binding arbitration", sondern als "administrative procedure " ausgestaltet, die den Weg zu den staatlichen Gerichten ausdrücklich offenläßt. Der praktisch ausgesprochen hohe Verbindlichkeitsgrad der Panel-Entscheidungen ergibt sich ausschließlich aus der Monopolstellung der ICANN im Hinblick auf die Akkreditierung von Registrierstellen für Domainnamen. ICANN verpflichtet diese Registrierstellen nämlich vertraglich, Entscheidungen von Panels nach der UDRP durch Löschung oder Übertragung der

109 Vgl. Davidson, Click and Commit, What Terms are Users Bound to When They Enter Web Sites?: Wm. Mitchell L. Rev. 26 (2000) $1171 \mathrm{ff}$; Das, Forum-Selection Clauses in Consumer Clickwrap and Browsewrap Agreements and the "Reasonably Communicated " Test: Wash. L. Rev. 77 (2002) $481 \mathrm{ff}$.

110 Zur Verbraucherschiedsgerichtsbarkeit und der Kritik an deren weitgehender Anerkennung vgl. Mahdi, Gateway to Arbitration, Issues of Contract Formation Under the U.C.C. and the Enforceability of Arbitration Clauses Included in Standard Form Contracts Shipped With Goods: Nw. U.L. Rev. 96 (2001) 403ff.; Senderowicz, Consumer Arbitration and Freedom of Contract, A Proposal to Facilitate Consumers' Informed Consent to Arbitration Clauses in Form Contracts: Colum. J.L. Soc. Probl. 32 (1999) 275ff.; Smith, Mandatory Arbitration Clauses in Consumer Contracts, Consumer Protection and the Circumvention of the Judicial System: DePaul L. Rev. 50 (2001) 1191ff.; Ware, Paying the Price of Process, Judicial Regulation of Consumer Arbitration Agreements: J. Disp. Resol. 2001, 89ff.; Alderman, Pre-Dispute Mandatory Arbitration in Consumer Contracts, A Call for Reform: Hous. L. Rev. 38 (2001) 1237ff.; Alle-Murphy, Are Compulsory Arbitration Clauses in Consumer Contracts Enforceable?, A Contractual Analysis: Temple L. Rev. 75 (2002) 125ff.; Cappalli, Arbitration of Consumer Claims, The Sad Case of Two-Time Victim Terry Johnson or Where have you Gone Learned Hand?: B. U. Pub. Int. L.J. 10 (2001) $366 \mathrm{ff}$.

111 New York Appellate Court: Brower v. Gateway 2000 Inc, 676 N.Y.S. 2d 569, 572 (1998); vgl. zum Problem der Kosten Scarpino, Mandatory Arbitration of Consumer Disputes, A Proposal to Ease the Financial Burden on Low-Income Consumers: Am. U.J. Gender Soc. Pol. L. 10 (2002) 679ff. 
streitgegenständlichen Domainnamen zu "vollstrecken", was zivilrechtlich einer Kündigung des Vertrages zwischen der Registrierstelle und dem Domaininhaber gleichkommt. Im Effekt wird hierdurch lediglich das Prozeßrisiko umgekehrt. Nicht mehr der Markeninhaber, der vor dem Panel eine Verletzung seiner Rechte nachgewiesen hat, sondern der Cybersquatter muß jetzt vor den staatlichen Gerichten klagen und trägt die damit verbundenen Rechtsanwendungs- und Rechtsdurchsetzungsrisiken ${ }^{112}$.

Aufgrund der verbreiteten Bedenken gegen eine über AGB eingeführte, bindende Verbraucherschiedsgerichtsbarkeit wird auch in der Diskussion um alternative Verbraucherschutzmodelle für den E-Commerce eher auf unverbindliche Streitschlichtung gesetzt ${ }^{113}$. Dem Verbraucher soll der Zugang zu den staatlichen Gerichten offenbleiben. Ein (gar nicht so) sanfter Zwang zur Inanspruchnahme von ADR (Alternative Dispute Resoution) ergibt sich für den Verbraucher schon aus der mangelnden Attraktivität des staatlichen Rechtswegs im Hinblick auf Dauer, Kosten und Rechtsunsicherheit bei der grenzüberschreitenden Rechtsverfolgung. Die Verbindlichkeit von Entscheidungen von ODR-Providern kann sich demgegenüber aus einer einseitigen vertraglichen Unterwerfung des Unternehmers ergeben, die etwa Voraussetzung der Teilnahme an einem Gütesiegelprogramm ist. Eine entscheidende Schnittstelle bilden zudem die E-Payment-Provider, also Kreditkartenunternehmen oder Marktplatzbetreiber. Diese können nämlich gegenüber dem Unternehmer vertraglich vorsehen, daß Entscheidungen akkreditierter ODR-Provider zu Rückbelastungen führen, und solche Rückbelastungen können im Kontokorrentverhältnis regelmäßig auch faktisch erfolgreich vollzogen werden. Selbst wenn ODR-Entscheidungen gegenüber dem Unternehmer nicht verbindlich wären, so würde auch hier jedenfalls das Prozeßrisiko umgekehrt. Klagen müßte jetzt der Unternehmer, während der Verbraucher von den Vorleistungsrisiken befreit wäre ${ }^{114}$.

112 Ausführlich Calliess, Reflexive Transnational Law 201ff. mit weiteren Nachweisen; kritisch gerade aufgrund der Tatsache, daß dieser faktische Zwang in seinen Auswirkungen dem Rechtszwang gleichkommt Froomkin, ICANN's »Uniform Dispute Resolution Policy«, Causes and (Partial) Cures: Brooklyn L. Rev. 67 (2002) 605ff.

113 Vgl. die Nachweise in N.91 sowie Europäische Kommission, Mitteilung zur Erweiterung des Zugangs der Verbraucher zur alternativen Streitbeilegung, KOM(2001)161 endg.; American Bar Association, Task Force on Electronic Commerce and Alternative Dispute Resolution, Adressing Disputes in Electronic Commerce, Final Report and Recommendations, September $2002<$ http://www.law.washington.edu/ABA-eADR/home.html $>$.

${ }_{114} \mathrm{Zu}$ den Problemen der Vollstreckung von ODR-Entscheidungen vgl. den ABA Report (vorige Note) S. 35ff., wo ausgeführt wird, daß sich bei den geringen Streitwerten im B2C-E-Commerce schon die Vollstreckung aus einem Schiedsspruch nach dem UNÜ nicht lohnt, weshalb die Verbraucherschiedsgerichtsbarkeit keine Option ist. Demgegenüber wird der Rückgriff auf Escrow-Services und das Credit-Card-Charge-Back-Verfahren empfohlen. Die weitgehende Unverbindlichkeit von Settlements sowie die fehlende Einbindung in alternative Vollstreckungsverfahren erscheint als Nachteil des ODR-Verfahrens von ECODIR: <www.ecodir.org/odrp/rules.htm>. 


\section{Zivilverfassung: Konstitutionalisierung verbraucherschützender Zivilregimes}

In der internationalen Diskussion um den Verbraucherschutz im elektronischen Geschäftsverkehr herrscht angesichts der beschriebenen Entwicklungen weitgehend Einigkeit darüber, daß die Etablierung solcher Schutzmechanismen im Wege der Selbstregulierung der Wirtschaft im Interesse der Verbraucher nicht nur zu begrüßen ist, sondern auch staatlich gefördert werden sollte ${ }^{115}$. Auf dem Gebiet des Verbrauchervertragsrechts tritt eine solche Entwicklung freilich zumindest potentiell in Konflikt zum traditionellen nationalstaatlichen Verbraucherschutzansatz. Während die lex mercatoria auf einer altehrwürdigen Tradition der kaufmännischen Selbstregulierung fußt und sich ihre staatliche Anerkennung aus einem fehlenden öffentlichen Interesse an der Anwendung staatlichen Handelsrechts rechtfertigt, insofern Kaufleute nicht als schutzbedürftig angesehen werden, stieße eine weitgehende Privatisierung des Verbrauchervertragsrechts auf ganz erhebliche Bedenken ${ }^{116}$.

Damit treten die wechselseitigen Beziehungen und Einflüsse zwischen staatlichen und transnationalen Verbraucherschutzregimes in den Vordergrund des Interesses. Handelt es sich bei den beschriebenen Phänomenen bloß um rechtlich irrelevante soziale Normkomplexe, um das staatliche Verbraucherschutzniveau lediglich erhöhendes oder ergänzendes soft law? Oder kann man die Entstehung von hard code in Form von transnationalen Rechtsordnungen beobachten, die das staatliche Recht in einem handfesten Wettbewerb faktisch zu verdrängen drohen? Wie steht es mit den Chancen, die entstehenden privaten Verbraucherschutzregimes im Sinne des Konzepts der regulierten Selbstregulierung staatlich zu beeinflussen? Die hier vertretene These lautet, daß die Etablierung effektiver verbraucherschützender Zivilregimes das nationale und internationale Verbrauchervertragsrecht jedenfalls für Teilbereiche des globalen E-Commerce - insbesondere auf formal organisierten virtuellen Markplätzen - faktisch verdrängen wird, weshalb das entstehende transnationale Verbrauchervertragsrecht der Einbettung in eine pro-

$115 \mathrm{Vgl}$. die OECD-Leitlinien für den Verbraucherschutz im Zusammenhang mit dem elektronischen Rechtsverkehr, Teil II, VI B. "Alternative Streitbeilegungsverfahren" (Guidelines for Consumer Protection in the Context of Electronic Commerce, adopted by the Council in December 1999 [C[99]184/FINAL]), erhältlich unter <www.oecd.org>; vgl. auch die Konferenzbeiträge in: $O E C D$, Building Trust in the Online Environment: Business to Consumer Dispute Resolution, Joint Conference of the OECD, HCPIL, ICC, The Hague, 11-12 December 2000, Report of the Conference, DSTI/ICCP/REG/ CP(2001)2; OECD, Consumers in the Online Market Place, OECD Workshop on the Guidelines - One Year Later, Report of the Workshop, 13-14 March 2001, Berlin, Germany, DSTI/CP(2001).

116 Vgl. European Consumer Law Group, Soft Law and the Consumer Interest, ECLG/ 071/2001 - March 2001; E-contracts: creating the conditions for consumer confidence, Paper presented at the Conference on E-contract, Brussels, 18 and 19 October 2001. 
zedurale Verfassung der Freiheit bedarf, die den Prozeß der Privatisierung des Zivilrechts zugleich ermöglicht und um die nötige Zivilisierung des Privatrechts ergänzt ${ }^{117}$.

Bei der insoweit notwendigen Konstitutionalisierung verbraucherschützender Zivilregimes ist zwischen einer inneren und einer äußeren Verfassung zu unterscheiden: die Entstehung eines transnationalen Verbrauchervertragsrechts als Rechtssystem ist einerseits durch Reflexivität im Sinne der Anwendung eines Prozesses auf sich selbst (z.B. Normieren des Normierens) gekennzeichnet, zivilgesellschaftliche Selbstorganisation konstituiert damit gleichsam von selbst eine innere Spontanverfassung von Privatregimes ${ }^{118}$. Andererseits bedürfen Privatregimes der Einbettung in eine äußere Rahmenordnung, die zivilgesellschaftliche Selbstorganisation als Ausübung von Privatund Parteiautonomie anerkennt und im Hinblick auf Gemeinwohl, Drittinteressen (alterius contractu nemo obligatur) und Gerechtigkeit (informed consent, unconscionability) ${ }^{119}$ einbindet und begrenzt. Private und öffentliche Verfassung fungieren hierbei als wechselseitige Auffangordnungen, wobei die Grenzen im Kontext einer global governance, die auf das Zusammenwirken staatlicher, wirtschaftlicher und zivilgesellschaftlicher Akteure setzt, $\mathrm{zu}$ hybriden Ordnungsstrukturen verschwimmen ${ }^{120}$, die hier zusammengenommen als Zivilverfassung bezeichnet werden ${ }^{121}$.

Zur Verdeutlichung sei wiederum auf den Präzedenzfall der lex mercatoria verwiesen: Das Element der Spontanverfassung findet sich dort in den verschiedenen Schiedsinstitutionen, die im Wettbewerb zwischen wirtschaftlichen for-profit-Akteuren (z.B. National Arbitration Forum) und zivilgesellLaw.

117 Vgl. Calliess, Globale Kommunikation (oben N. 1) und ders., Reflexive Transnational

118 Zum Begriff der Spontanverfassung vgl. Teubner (oben N. 32); zu den ökonomischen Vorbildern der Unterscheidung von innerer Spontanverfassung und äußerer Rahmenordnung bei Hayek und Lachenmann vgl. Okruch, Innovation und Diffusion von Normen (1999).

119 Gemeint sind die vornehmlich im BGB Allgemeiner Teil und den Verbraucherschutzvorschriften niedergelegten prozeduralen Bedingungen der Gültigkeit von Verträgen, vgl. Calliess, Die Zukunft der Privatautonomie, Zur neueren Entwicklung eines gemeineuropäischen Rechtsprinzips: Jb. Junger Zivilrechtswiss. 2000 (2001) 85ff.; zu den entsprechenden Bedingungen der contract formation im amerikanischen Recht vgl. nur Balloon, From Wax Seals to Hypertext: Electronic Signatures, Contract Formation, and a New Model for Consumer Protection in Internet Transactions: Emory L.J. 50 (2001) 905.

$120 \mathrm{Vgl}$. Engel, Hybrid Governance Across National Jurisdictions as a Challenge to Constitutional Law (Gemeinschaftsgüter - Recht, Politik und Ökonomie, 2001/8). ders., A Constitutional Framework for Private Governance (2001) (Preprints aus der Max-PlanckProjektgruppe Recht der Gemeinschaftsgüter, 2001/4).

121 Zum Begriff der Zivilverfassung ausführlich Calliess, Das Zivilrecht der Zivilgesellschaft, in: Rechtsverfassungsrecht, Recht-Fertigung zwischen Privatrechtsdogmatik und Gesellschaftstheorie, hrsg. von Joerges/Teubner (2003) 239ff.; Teubner, Globale Zivilverfassungen, Alternativen zur staatszentrierten Verfassungstheorie: ZaöRV 63 (2003) 1-28. 
schaftlichen not-for-profit-Akteuren (International Chamber of Commcerce [ICC], American Arbitration Association [AAA]) Schiedsordnungen bereitstellen, die das nationalstaatliche (10. Buch der ZPO) und internationale (UNÜ) Recht als öffentliche Verfassung ergänzen. Der hybride Charakter der Zivilverfassung der lex mercatoria kommt vor allem darin zum Ausdruck, daß klassische internationale Organisationen softlaw produzieren (UNCITRAL-Modellgesetz) oder sogar außerhalb ihres mitgliedstaatlichen Auftrags als private Normunternehmer (UNIDROIT Principles) mit anderen zivilgesellschaftlichen Akteuren (Lando Commission; CENTRAL) konkurrieren. Offensichtlich ist der hybride Charakter von Zivilverfassungsrecht auch im Falle der UDRP, die aufgrund eines White Paper der US-Regierung mit Unterstützung der WIPO als Vertragsregime einer privaten not-for-profitOrganisation (ICANN) etabliert wurde ${ }^{122}$.

Bei der Etablierung einer Zivilverfassung für ein transnationales Verbrauchervertragsrecht geht es ganz maßgeblich um die Begründung reflexiver Institutionen, die die beschriebenen Phänomene in einer Art und Weise organisieren, die einerseits einen effektiven Rechtsschutz durch alternative Verbraucherschutzmechanismen fördern und anderseits die Fairneß und Gerechtigkeit solcher Verfahren gegenüber dem Verbraucher gewährleisten. Im folgenden werden einige Ansätze dazu vorgestellt.

\section{Verbraucherschiedsgerichtsbarkeit: "Consumer \\ Due Process Protocol« der AAA}

Im Zusammenhang mit der oben dargestellten Diskussion um die Zulässigkeit und Fairneß einer in AGB vorgesehenen mandatory, pre-dispute, and binding consumer arbitration ist es interessant, daß die bedeutendste Schiedsinstitution in den USA, die American Arbitration Association, im April 1998 ein "Consumer Due Process Protocol" verabschiedet hat, welches u.a. vorsieht, daß Schiedsklauseln in AGB deutlich hervorgehoben sein müssen (Principle 11), und daß die mit der Durchführung des Schiedsverfahrens verbundenen Kosten für den Verbraucher angemessen sein müssen (Principle 6). Die AAA hat dieses Protokoll durch die »Supplementary Procedures for Consumer-Related Disputes" vom März 2002 umgesetzt, die die Kosten des Verbrauchers bei Streitwerten bis zu 10.000 \$auf 175 \$ beschränken, während der Unternehmer die übrigen Kosten trägt. Zudem hat die AAA eine Musterschiedsklausel entworfen, die den Verbraucher deutlich hervorgehoben und verständlich über die Tragweite der Klausel, die Möglichkeit des alternativen Zugangs zu den Small Claims Courts und weitere Informationsquellen zu seinen Rechten informiert. Die AAA lehnt die Durchführung von Schiedsverfahren ab, soweit die Schiedsklausel diesen Vorgaben nicht ent-

122 Ausführlich mit Nachweisen Calliess, Reflexive Transnational Law. 
spricht und sich der Unternehmer nicht dem Protokoll unterwirft ${ }^{123}$. Da viele amerikanische Unternehmen in ihren Schiedsklauseln die AAA als Schiedsinstitution benennen ${ }^{124}$, wird sich das Protokoll in der Praxis voraussichtlich durchsetzen.

\section{Online-Streitschlichtung: ABA Best Practices und i-ADR-Center}

Die »Task Force on Electronic Commerce and Alternative Dispute Resolution" der American Bar Association hat in ihrem Abschlußbericht vom September $2002^{125}$ ausführlich zu den Problemen von alternativen Streitschlichtungsverfahren für den globalen E-Commerce Stellung genommen. Die Kommission diskutiert insbesondere die Idee der Etablierung eines Trustmark, das an akkreditierte ODR Service Provider vergeben wird, die in einem Code of Conduct niedergelegte Anforderungen an die Fairneß solcher Verfahren erfüllen. Im Ergebnis wird ein solches Projekt allerdings zum gegenwärtigen Zeitpunkt als verfrüht verworfen. Denn ODR-Services befänden sich immer noch in einem sehr frühen Stadium, so daß zunächst die weitere Entwicklung in der Praxis abgewartet werden müsse. Vorrangig sei zunächst die Streitvermeidung durch effektive Kundenbeschwerdesysteme auf seiten der Unternehmer (Customer Relationship Management). Als "unverbindliche Orientierung « für ODR Service Provider, Verbraucher und Trustmarkprovider hat die Kommission jedoch »Recommended Best Practices by Online Dispute Resolution Service Providers ${ }^{126}$ veröffentlicht, die vorsehen, daß ein ODR Service Provider seine Nutzer über alle wesentlichen, die Fairneß des Verfahrens betreffenden Merkmale in transparenter Weise informieren soll. Zudem wird die Einrichtung eines i-ADR-Center (International Alternative Dispute Resolution Center) vorgeschlagen, welches Informationen über verfügbare Streitschlichtungsverfahren webbasiert konsolidieren soll. Ein solches Informationszentrum kann in Zukunft als

123 Die Supplementary Rules sowie das Consumer Due Process Protocol mit Erläuterungen und Musterklausel sind über die Website der AAA < www.adr.org > erhältlich.

${ }^{124}$ Neben der AAA ist vor allem das National Arbitration Forum (NAF) von Relevanz; vgl. etwa Scarpino (oben N. 111) 680. Eine entsprechende Klausel, die freilich dem Protokoll noch nicht entspricht, findet sich z.B. in den terms \& conditions von Amazon.com. Das Protokoll kann daher auch für deutsche Kunden von Amazon.com relevant werden, da $\$ 1031 \mathrm{ZPO}$ in diesem Falle nicht anwendbar ist und sich ein Gerichtsstand von Amazon.com mangels Niederlassung in Deutschland nur schwer begründen ließe.

${ }^{125}$ American Bar Association, Task Force on Electronic Commerce and Alternative Dispute Resolution (oben N.113) < http://www.law.washington.edu/ABA-eADR/ home.html>.

${ }^{126}$ American Bar Association, Task Force on Electronic Commerce and Alternative Dispute Resolution, Recommended Best Practices by Online Dispute Resolution Service Providers, September $2002<$ http://www.law.washington.edu/ABA-eADR/home. html>. 
Grundlage für die weitergehenden Ideen eines Dispute-Clearinghouse oder eines ODR-Trustmark-Centers dienen.

\section{Trustmark of Trustmarks: Mindeststandards hybrider Organisationen}

Um die Transparenz im Bereich der Trustmarkanbieter zu erhöhen und gewisse Mindestanforderungen hinsichtlich der verwendeten Codes of Conduct zu etablieren, wurde die Idee von reflexiven Trustmarks entwickelt, die im Zusammenwirken von Staat, Industrie und Verbraucherverbänden eingerichtet werden ${ }^{127}$. So beruht das e-Confidence project auf einer gemeinsamen Initiative der Europäischen Kommission und den Industrie- und Verbraucherverbänden UNICE und BEUC mit dem Ziel, ein sekundäres europäisches Trustmark zu etablieren, für welches sich primäre Trustmark und ODR Service Provider akkreditieren lassen können, soweit diese die European Trustmark Requirements (ETR) erfüllen. Das von UNICE und BEUC ausgehandelte Dokument enthält detaillierte Anforderungen nicht nur prozeduraler, sondern auch materialer Art und folgt vergleichbar dem i-ADR-Center dem Ziel, die Transparenz und damit den Zugang der Verbraucher zu alternativen Streitschlichtungsverfahren zu verbessern ${ }^{128}$. Seit der Bekanntgabe des Programms im Oktober 2001 sind - soweit ersichtlich - allerdings keine weiteren Schritte zur Einrichtung des Systems erfolgt, was u.a. in dem verfolgten Ansatz, die gesetzlichen Mindestanforderungen an den Verbraucherschutz auf freiwilliger Basis nochmals zu überbieten, begründet liegen mag.

Ein vergleichbares Konzept wurde allerdings im Vereinigten Königreich realisiert, wo die Regierung im Zusammenwirken mit der Electronic Business Alliance und der Consumers Association eine not-for-profit-Organisation namens TrustUK eingerichtet hat, bei der sich Verwender von Codes of Conduct für den E-Commerce akkreditieren lassen können, wenn sie gewisse Minimumstandards erfüllen ${ }^{129}$. Zu den bisher akkreditierten Zivilregimes gehört u.a. Webtrader, ein Programm welches im Zusammenwirken verschiedener Verbraucherverbände aus Belgien, Frankreich, Italien, den Niederlanden, Portugal, Spanien und England entwickelt wurde ${ }^{130}$. Erwähnt seien noch entsprechende Initiativen zu Mindeststandards für Trustmarks des Global Business Dialogue on E-Commerce sowie in Deutschland der Initiative-D21 $1^{131}$.

127 Es existiert eine Vielzahl von Initiativen, die hier nicht dargestellt werden können. Ein (schon nicht mehr aktueller) Überblick bei de Bruin (oben N. 91) $182 \mathrm{ff}$.

${ }_{128}$ Search Google.de »e-Confidence project«: dort UNICE BEUC Paper; FEDMA Press Release vom 8.11. 2001: < www.fedma.org/img/db/81101econfidence.pdf>.

$129 \mathrm{Vgl}$. <www.trustuk.org.uk $>$.

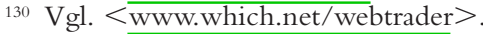

$131 \mathrm{Vgl}$. $<$ www.gbde.org trustmarks $>$ sowie $<$ www.initiatived21.de $>$ Qualitätskriterien für Gütesiegel-Anbieter. 


\section{Staatliches Soft-Law und Infrastruktur: EG-Empfehlungen und EEJ-Net}

Wie bereits erwähnt verfolgt die EU seit längerem das Ziel, den Zugang der Verbraucher zum Recht insbesondere bei grenzüberschreitenden Verbraucherverträgen auch durch Förderung von außergerichtlichen Streitschlichtungssystemen zu fördern. Diesbezüglich hat die Europäische Kommission insbesondere zwei Empfehlungen betreffend die Grundsätze für Einrichtungen, die für die außergerichtliche Beilegung von Verbraucherrechtsstreitigkeiten zuständig sind $(98 / 257 / \mathrm{EG})^{132}$, sowie für an der einvernehmlichen Beilegung von Verbraucherrechtsstreitigkeiten beteiligte außergerichtliche Einrichtungen $(2001 / 310 / E G)^{133}$, veröffentlicht ${ }^{134}$, die ihrem Inhalt nach den Best Practices der ABA vergleichbar Grundsätze der Verfahrensfairneß niederlegen. Diese Grundsätze sind nur insofern verbindlich, als ihre Beachtung Voraussetzung für die Teilnahme der Verfahren am EEJ-Net sind, welches vergleichbar dem ABA-i-ADR-Center als Informations- und Anlaufstelle dient ${ }^{135}$. Die oben vorgenommene kritische Einschätzung der Erfolgsaussichten dieses Netzes bezieht sich auf die Tatsache, daß das EEJ-Net nicht spezifisch für ODR-Verfahren, sondern für Offline-Verfahren geschaffen wurde, deren Inanspruchnahme ausgesprochen umständlich ist. Die Kommission hat aber die Absicht geäußert, in Zukunft auch spezielle Maßnahmen zur Förderung der Online-Streitschlichtung zu ergreifen ${ }^{136}$. Die Kommission hält rechtliche Maßnahmen auf diesem Gebiet allerdings gegenwärtig ebenfalls für verfrüht und beschränkt sich auf die Förderung von Selbstregulierungsinitiativen zwischen Industrie und Verbrauchern. Diese Politik kommt in Artt. 16 und 17 der E-Commerce Richtlinie (2000/31/ EG) zum Ausdruck, wo zur Ausarbeitung und Beachtung von Verhaltenskodizes sowie zur Etablierung angemessener Verfahrensgarantien bei der außergerichtlichen Streitschlichtung »ermutigt« wird, während den Mitgliedstaaten untersagt wird, ODR-Verfahren zu erschweren.

\section{Staatliche Anreize und Akkreditierung verbraucherschützender Zivilregimes}

Vor dem Hintergrund der oben angesprochenen potentiellen Behinderung des grenzüberschreitenden E-Commerce durch das Verbraucherlandprinzip ist die nunmehr in Art. 15 I c) EuGVVO enthaltene Erweiterung des

132 ABl. EG 1998 L 115/31.

133 ABl. EG 2001 L 109/56.

134 Vgl. dazu die Mitteilungen der Kommission KOM(1998)198 und KOM(2001)161.

135 Siehe ausführlich die Darstellung im Grünbuch (oben N. 86) mit weiteren Nachweisen.

136 Vgl. die Andeutungen im Grünbuch (oben N. 86); vgl. auch Mitteilung vom 28. 5. 2002, eEurope 2005 (oben N.63), sowie Verbraucherpolitische Strategie (oben N. 55). 
Verbrauchergerichtsstandes (jede »Ausrichtung« eines Angebots auf den Verbraucherstaat genügt) ${ }^{137}$ im Vorfeld nicht unumstritten geblieben ${ }^{138}$. Die (englische) Berichterstatterin des zuständigen Ausschusses des Europäischen Parlaments hatte in ihrem Bericht eine Änderung vorgeschlagen, nach der der Verbrauchergerichtsstand im E-Commerce nach ausdrücklicher Information und separater Zustimmung des Verbrauchers abbedungen werden kann, wenn der Anbieter sich im Gegenzug verpflichtet, Streitigkeiten in einem anerkannten außergerichtlichen Schlichtungsverfahren geltend zu machen. Die Kommission wird aufgefordert, entsprechende Verbraucherschlichtungsinstanzen und Gütesiegel zu akkreditieren ${ }^{139}$. Die im Ausschuß mit knapper Mehrheit angenommen Änderungen wurden in der ersten Lesung im Parlament allerdings nur teilweise übernommen, Kommission und Rat haben diese Vorschläge im weiteren Verlauf nicht berücksichtigt ${ }^{140}$. In einer Rede vor den Parlamentariern hatte der zuständige Kommissar Byrne diese Vorschläge vor allem deshalb abgelehnt, weil entsprechende Schlichtungsinstanzen nicht etabliert seien, eine staatliche Akkreditierung mithin ausscheide. Einigkeit bestand aber im Hinblick auf die weitere Förderung solcher Verfahren ${ }^{141}$.

Unabhängig von der konkreten Ausgestaltung des Vorschlags des Parlaments ist die Idee, den Unternehmern einen Anreiz (Zulässigkeit einer Gerichtstandsvereinbarung) zur Verfügung zu stellen, insofern sich diese im Gegenzug einem anerkannten ODR-Verfahren unterwerfen, auf dessen Fairneß der Staat im Wege der Akkreditierung einen erheblichen Einfluß hat, generalisierbar. Das Anreizmodell entspricht auch dem Modell der Schiedsgerichtsbarkeit, wo die staatliche Anerkennung und Vollstreckung von Schiedssprüchen mit der Beachtung der in den Schiedsgesetzen niedergelegten rechtsstaatlichen Mindestanforderungen (due process) verknüpft wird. Demgegenüber folgt $\$ 15$ a EGZPO, der gem. Abs. 2 Satz 2 ohnehin nur Anwendung

137 Zur Interpretation des Wortes "Ausrichten« im Kontext des E-Commerce vgl. die Gemeinsame Erklärung von Rat und Kommission zu Artt. 15 und 73 EuGVVO, aufgenommen in das Protokoll der Ratstagung vom 22.12.2000, < http://europa.eu.int/comm/ justice_home/unit/civil_de.htm $>$, wo ausgeführt wird, daß es einer interaktiven Homepage bedarf, die in der Folge tatsächlich zum Vertragsschluß im Fernabsatz geführt hat.

${ }_{138}$ Vgl. nur Spindler, Internationales Verbraucherschutzrecht im Internet, Auswirkungen der geplanten neuen Verordnung des Rates über die gerichtliche Zuständigkeit und die Anerkennung und Vollstreckung von Entscheidungen in Zivil- und Handelssachen: Multimedia und Recht (MMR) 2000, 18ff.; Mankowski, E-Commerce und Internationales Verbraucherschutzrecht (2000) 22ff. (MMR-Beilage, 7/2000).

139 Report of Diana Wallis (ELDR, UK), 18.9. 2000 (PE A5-253/2000).

140 Vgl. die Stellungnahme des Parlaments, ABl. EG 2001 C 146/94 sowie den überarbeiteten Kommissionsentwurf, $\operatorname{KOM}(2000) 689$ vom 26.10. 2000.

${ }_{141}$ Byrne, Cyberspace and Consumer Confidence [Rede vom 18. 9. 2000] (erhältlich auf der Homepage der DG Sanco < http://europa.eu.int/comm/consumers/>; vgl. auch die Gemeinsame Erklärung des Rates und der Kommission zu Artt. 15 und 73 der Verordnung (oben N. 137). 
findet, wenn die Parteien in demselben Bundesland wohnen, eher einem traditionellen Regulierungsansatz, wenn der Zugang zu staatlichen Gerichten zwingend vom Scheitern einer einvernehmlichen Beilegung vor einer staatlich anerkannten oder sonstigen Gütestelle abhängig gemacht wird ${ }^{142}$.

\section{Verbraucherschutz im Wettbewerb transnationaler Zivilregimes: ein Ausblick}

Zum gegenwärtigen Zeitpunkt erscheint es als verfrüht, von der Existenz eines transnationalen Verbrauchervertragsrechts als einem Rechtssystem jenseits der staatlichen Privatrechtsordnungen $\mathrm{zu}$ sprechen ${ }^{143}$. Indes hat sich gezeigt, daß im globalen B2C-E-Commerce Phänomene der Selbstregulierung beobachtet werden können, die jedenfalls im Ansatz jenen Entwicklungen im internationalen Handelsverkehr vergleichbar sind, auf die sich die Rede von der lex mercatoria als einem transnationalen Handelsrecht stützt. Dies gilt für alle drei Ebenen, auf die sich eine Privatisierung von Recht bezieht, nämlich die private Normsetzung, die private Streitschlichtung und die privat organisierte Vollstreckung ${ }^{144}$. Wenn sich die Emergenz privater Ordnung wesentlich als konfliktgetrieben darstellt, dann ist die Verdichtung dieser Phänomene in Richtung auf eine transnationale Rechtsordnung abhängig von der weiteren Verbreitung grenzüberschreitender Verbraucherverträge im globalen E-Commerce. Das Internet selbst hat an diesem Prozeß auch insoweit einen Anteil, als es die formale Organisation und damit die nicht nur spontan-zufällige Selbstorganisation von transnationalen Transaktionen durch Vernetzung und Schaffung virtueller Räume begünstigt. Dabei ist es weniger ein privat geschaffenes globales Einheitsrecht als ein Wettbewerb verschiedener transnationaler Zivilregimes, der sich am Horizont abzeichnet.

Versteht man diesen institutionellen Wettbewerb positiv als Entdeckungsverfahren, so ist es grundsätzlich zu begrüßen, daß dieser nicht an den Anforderungen des Marktes vorbei durch eine verfrühte staatliche Rahmengesetzgebung behindert wird. Selbstregulierung kann grundsätzlich nicht staatlich verordnet werden, eine staatliche Überregulierung behindert nicht nur den institutionellen Wettbewerb, sondern kann auch den mit Selbstregulierungsmechanismen verbundenen Vorteil der self-enforcing arrangements zerstören $^{145}$. Andererseits ist das Funktionieren von Wettbewerb auf Märkten

$142 \mathrm{Vgl}$ dazu N.85.

143 Für eine detaillierte Analyse der Voraussetzungen des Übergangs von einem sozialen Normarrangement zu einem transnationalen Rechtssystem vgl. Calliess, Reflexive Transnational Law $185 \mathrm{ff}$.

$144 \mathrm{Zu}$ dieser Kategorisierung vgl. Hadfield (oben N. 53) und Mefford (oben N. 103).

145 Vgl. dazu grundsätzlich Teubner, Steuerung durch plurales Recht, Oder: Wie die Politik den normativen Mehrwert der Geldzirkulation abschöpft, in: Die Modernisierung 
grundsätzlich an das Vorhandensein von hinreichender Information und Transparenz gebunden ${ }^{146}$. Zur Vermeidung der mit Informationsasymmetrien verbundenen Probleme ist es deshalb konsequent, wenn die diskutierten Instrumente zum Verbraucherschutz im E-Commerce vornehmlich Informationsregeln sowohl primär im Hinblick auf Verträge mit Unternehmern ${ }^{147}$, als auch sekundär im Hinblick auf die Dienstleistungen von Normunternehmern (Trustmarks) und Streitschlichtern (ODR) etablieren ${ }^{148}$.

Freilich ist aus der ökonomischen Theorie bekannt, daß das Vorhandensein von Informationen allein nicht ausreicht, wenn diese Informationen vom Verbraucher nicht zu angemessenen Kosten verarbeitet werden können, was gemeinhin im Falle von AGB angenommen wird und zur Rechtfertigung der Einbeziehungs- und Inhaltskontrolle führt ${ }^{149}$. Auch im Hinblick auf Verkaufsprospekte und Börseninformationspflichten (insbesondere Ad-hocMitteilungen) werden die Grenzen des Anlegerschutzes durch Information diskutiert, wobei andererseits argumentiert wird, daß der vermeintliche information overload eine wichtige Grundlage für Informationsintermediäre ist, die die Datenflut aufgrund ihrer Expertise auswerten können, um das Ergebnis ihrer Analyse in einfach verständliche Bewertungen verpackt an Anleger und Verbraucher weiterzugeben. Als Informationsintermediäre können sowohl Händler und Vermittler (z.B. Banken, Versicherungsvertreter, unabhängige Finanzvermittler) als auch reine Informationsdienstleister (z.B. Rating-Agenturen, »Stiftung Warentest», Zeitungen, nicht provisionsgebundene Finanzberater) auftreten. Die von der Prinzipal-Agent-Theorie adressierten Probleme der Informationsasymmetrien zwischen Verkäufer und Käufer treten freilich im Verhältnis von Intermediär und Käufer wieder auf. In den unterschiedlichen Formen der Finanzierung der Information (Identität von Verkäufer und Intermediär, provisionsgebundene Intermediäre, Käufer zahlt Intermediär) angelegte Interessenkonflikte können dann selbst Gegenstand von Regulierung sein, etwa durch Informationspflichten der Intermediäre bezüglich potentieller Interessenkonflikte, durch Bezeichnungsschutz für und Zertifizierung von Intermediären, die bestimmte Anforderungen an die

moderner Gesellschaften, hrsg. von Wolfgang Zapf (1990) 528ff. (Verhandlungen des 25. Deutschen Soziologentages); Calliess, Prozedurales Recht (oben N. 43) 191ff., $257 \mathrm{ff}$. (am Beispiel der medizinischen Ethikkommissionen).

${ }_{146} \mathrm{Vgl}$. die Beiträge von Kerber/Vanberg, Ulen, sowie Wein, Consumer Information Problems, Causes and Consequences, in: Party Autonomy and the Role of Information in the Internal Market, hrsg. von Grundmann/Kerber/Weatherill (2001).

${ }_{147} \mathrm{Vgl}$. dazu die Anforderungen im Teil I der OECD Guidelines (oben N. 115) sowie die Vorgaben der E-Commerce-Richtlinie (2000/31/EG) (oben N. 64).

148 Vgl. dazu die Recommended Best Practices der ABA (oben N. 126).

${ }_{149}$ Vgl. Wein (oben N. 146) 80ff.; Wolf, Party Autonomy and Information in the Unfair Contract Terms Directive: ebd. 313ff.; Schäfer/Ott, Lehrbuch der ökonomischen Analyse des Zivilrechts ${ }^{3}$ (2000) $478 \mathrm{ff}$. 
Unabhängigkeit erfüllen, oder durch Festlegung verbindlicher Qualitätsstandards als allgemeine Zulassungsvoraussetzung ${ }^{150}$.

Vor diesem Hintergrund können die im globalen E-Commerce tätigen Betreiber von virtuellen Marktplätzen und die Anbieter von Gütesiegeln als Informationsintermediäre verstanden werden, die mit ihren Safe HarbourPolicies sowie mit der Prüfung und Akkreditierung einzelner Unternehmern auf der Grundlage von Codes of Conduct einfach verständliche Informationen (Gütesiegel) über die mit einer Transaktion verbundenen Risiken herstellen. Das so produzierte generalisierte Verbrauchervertrauen wird an die Anbieter von Waren und Dienstleistungen über Festgebühren oder Umsatzbeteiligungen verkauft ${ }^{151}$. Die damit begründeten Interessenkonflikte erscheinen so lange als unproblematisch, wie der Markt für Internetmarktplätze und Trustmarkprovider selbst transparent bleibt, so daß der Verbraucher eine informierte Wahl zwischen verschiedenen Zivilregimes mit unterschiedlichen Verbraucherschutzniveaus treffen kann und im Falle auftretender Probleme bei der Sicherstellung der Einhaltung der Safe Harbour-Policies bzw. der Codes of Conduct im Zweifelsfalle den Anbieter wechseln kann ${ }^{152}$.

Angesichts der gegenwärtig zu beobachtenden Proliferation von Gütesiegelprogrammen und der Tatsache, daß die Qualität dieser Programme im Hinblick auf die Kontrolle der Einhaltung der in einem Code niedergelegten Anforderungen sowie die Fairneß von integrierten Streitschlichtungsverfahren vom Verbraucher jedenfalls nicht im vorhinein beurteilt werden kann ${ }^{153}$, scheint die Etablierung von Informationsplattformen (i-ADR-Center) und reflexiven Trustmarkprogrammen (TrustUK) eine wesentliche Bedingung ei-

${ }^{150}$ Vgl. ausfuhhrlich Grundmann/Kerber, Information Intermediaries and Party Autonomy, The Example of Securities and Insurance Markets, in: Party Autonomy and the Role of Information in the Internal Market (oben N. 146) 264ff. mit weiteren Nachweisen.

151 Das ist jedenfalls die Regel und anscheinend die solideste Finanzierungsform, während rein werbefinanzierte Internetportale häufig Probleme haben und der Nutzer (Verbraucher) im Internet bisher überhaupt nicht zur Zahlung für gute Information bereit zu sein scheint. Letzteres mag sich mit der Einführung sicherer und zugleich kostengünstiger elektronischer Bezahlmethoden ändern. Die "Stiftung Warentest« bietet etwa Testberichte gegen Bezahlung im Internet über Firstgate an.

${ }^{152}$ Es dürfte jedenfalls einleuchten, daß der Verbraucher den Markt der Intermediäre leichter überblicken und bewerten kann als den Markt aller Primäranbieter. Zu den möglichen Interessenkonflikten vgl. ausführlich OECD, Building Trust in the Online Environment: Business to Consumer Dispute Resolution, Joint Conference of the OECD, HCOPIL,ICC, The Hague, 11-12 December 2000, Report of the Conference, DSTI/ICCP/ REG/CP(2001)2; vgl. auch den Tagungsbericht "Online Alternative Dispute Resolution", 28.9. 2001, BMWi, Berlin, <www.initiatived21.de>.

153 Bei den Dienstleistungen von Informationsintermediären handelt es sich eher um credence goods als um experience goods; vgl. Grundmann/Kerber (oben N.150) 279. Das gilt vorliegend jedenfalls für Trustmark-Anbieter, während man die Qualität von ODRVerfahren zwar durch Erfahrung halbwegs einschätzen kann, allerdings erst, wenn es für Alternativen zu spät ist. 
nes funktionsfähigen Wettbewerbs transnationaler Zivilregimes zu sein. Dabei dürfte es ausreichen, wenn solche reflexiven Programme im Sinne der Beseitigung von informationellem Marktversagen vor allem Informationsanforderungen aufstellen (ABA Recommended Best Practices) und die teilnehmenden Zivilregimes auf der Grundlage von unverbindlichen Empfehlungen (EG-Empfehlungen) in Form eines Rating kategorisieren. Demgegenüber würde eine Festlegung von materiellen Mindestanforderungen mit dem Ziel, das staatlich vorgeschriebene Verbraucherschutzniveau nochmals zu überbieten (e-Confidence project), die Gefahr einer ineffizienten Überregulierung (race to the top) begründen und den institutionellen Wettbewerb als Entdekkungsverfahren für ein effizientes Verbraucherschutzniveau durch Versteinerungseffekte behindern.

Zur Meidung von Interessenkollisionen sollte ein reflexiver Trustmark allerdings von einer zivilgesellschaftlichen not-for-profit-Institution getragen werden, die im Wege der Co-Regulierung zwischen Staat, Industrie und Verbraucherverbänden zu etablieren wäre. Als wichtige global players haben sich auf diesem Gebiet insbesondere die OECD, der Global Business Dialogue on E-Commerce (GBDe) und Consumers International etabliert ${ }^{154}$. Der GBDe hat sich diesbezüglich im November 2003 mit Consumers International auf "Alternative Dispute Resolution Guidelines" geeinigt, die eine Reihe von Empfehlungen an Internet-Händler, ADR-Anbieter und die Regierungen enthalten ${ }^{155}$.

Von einem transnationalen Verbrauchervertragsrecht wird man im Ergebnis erst sprechen können, wenn sich die im Wettbewerb der verbraucherschützenden Zivilregimes herausprozessierenden best practices zu Prinzipien und Grundregeln grenzüberschreitender Verbraucherverträge verdichten, die die gesellschaftliche Praxis des Abschlusses solcher Verträge und die alternative Streitschlichtung tatsächlich anleiten. Der Unterschied zwischen sozialen Praktiken der alternativen Streitschlichtung und einem Rechtssystem besteht nämlich wesentlich in der Produktion von Rechtssicherheit als dem gesellschaftlichem Mehrwert, der sich aus der Kondensation und Konfirmation von Normen anläßlich der öffentlichen Entscheidung über private Konflikte ergibt. Daraus folgt nicht notwendig, daß Entscheidungen von ODRProvidern im Volltext veröffentlicht werden müssen. Allerdings muß die im Hinblick auf die Parteien gegebenenfalls anonymisierte ratio decidendi solcher Entscheidungen allgemein zugänglich sein, wenn sich ein transnationa-

154 Eine aktuelle Übersicht über die Aktivitäten der OECD findet sich in »Consumers in the Online Marketplace The OECD Guidelines three Years later, Report by the Committee on Consumer Policy, 3 February 2003, DSTI/CP(2002)4/FINAL < www.oecd.org>; zum Global Business Dialogue on Electronic Commerce (oben N.93) vgl. $<$ www.gbde.org $>$; siehe auch $<$ www.consumersinternational.org $>$.

155 Siehe $<$ www.gbde.org/adragreement03.pdf $>$. 
les Verbrauchervertragsrecht als autonomer, i.e. operativ geschlossener Rechtsdiskurs etablieren soll ${ }^{156}$.

In diesem Prozeß mögen sich einzelne Vertragsklauseln gewohnheitsrechtlich als materiellrechtlicher Mindeststandard etablieren, hingegen ist es nicht erforderlich, daß nach dem Vorbild der staatlichen Verbrauchervertragsrechte weitgehend zwingende materielle Lösungen für Verbraucherschutzprobleme vorgegeben werden. Ein transnationales Rechtssystem kann und - wie die oben diskutierten Beispiele zeigen - wird sich voraussichtlich weitgehend in den prozeduralen Aspekten eines Zivilverfassungsrechts erschöpfen. Denn im Gegensatz zu den regional stark divergierenden Lösungen des mandatory consumer law bildet das facilitative consumer law gleichsam den Common Core der nationalen Verbrauchervertragsrechte, für den sich der nötige rough consensus über die Prinzipien eines Weltverbrauchervertragsrechts mit Aussicht auf Erfolg besorgen läßt ${ }^{157}$.

156 Ausführlich Calliess, Reflexive Transnational Law 185ff., 200f., 205.

157 Zur Unterscheidung von mandatory und facilitative law vgl. nur Wein (oben N. 146); aus diesem Grund überwiegt schon auf europäischer Ebene das Vertragsinformationsrecht; vgl. Grundmann, Europäisches Verbrauchervertragsrecht im Spiegel der ökonomischen Theorie, in: Vereinheitlichung und Diversität des Zivilrechts (oben N. 7) 284ff.; zu den Erfolgsaussichten einer Verdichtung/Konkretisierung der Verbraucherschutzprinzipien in den OECD Guidelines vgl. auch OECD, The Guidelines three Years later (oben N. 154) S. 10 . 